\title{
El caso de «Italia 90». Actores y políticas en una intensa experiencia de Gobierno local
}

SUMARIO: 1. ADVERTENCIAS PARA UNA EXPLORACION. 2. EL FUTBOL COMO POLICY AREA. 3. LOS ACTORES POLITICO-ADMINISTRATIVOS. 3.1. El administrador local. 3.2. Burócratas, revisores, magistrados. 3.3. Los partidos. 4. LOS «ARQUITECTOS». 5. LAS EMPRESAS CONSTRUCTORAS. 6. LOS EQUIPOS DE FUTBOL DE LAS DOCE CIUDADES. 7. LOS INTERESES «AJENOS». 8. CONCLUSIONES.

\section{ADVERTENCIAS PARA UNA EXPLORACION}

Las decisiones relacionadas con la construcción de los estadios del campeonato mundial de fútbol «Italia 90» en las doce ciudades * que debían de albergar las competiciones se pueden resumir en cuatro grupos de variables elementales:

a) Los varios y múltiples actores que participan en la formación de las decisiones.

b) Las demandas, necesidades y oportunidades presentes en la base de los problemas de donde han partido los diversos procesos decisionales.

c) Las interacciones producidas entre los actores implicados en función de sus respectivos objetivos.

* (N. del T.) El autor se refiere a las ciudades de Milán, Turín, Génova, Udine, Verona, Bolonia, Florencia, Roma, Nápoles, Bari, Palermo y Cagliari, que en 1990 albergaron las competiciones del Campeonato Mundial de Fútbol «Italia 90» en estadios de fútbol de nueva construcción o salidos de remodelaciones profundas de los estadios ya existentes. 
d) Los resultados que las interacciones han producido: como efectos generales y sustantivos de los varios procesos decisionales y como efectos de la conducta de cada actor en relación a los objetivos perseguidos.

También deberemos tener en cuenta las relaciones que podemos suponer existirán entre esos cuatro grupos de variables.

Serán los actores los que contribuirán a determinar el problema que servirá de fundamento a la decisión. Son unos determinados protagonistas y no otros los que intervienen para poner de relieve, definir, volver a definir, transformar, articular, fragmentar, agregar y volver a agregar los términos del problema en cuestión a través de las mil posibles eventualidades y circunstancias, previstas, deseadas o inesperadas, que marcan el devenir real del proceso decisional y que hacen que su posterior implementación esté siempre abierta a posibles reformulaciones.

Al mismo tiempo, es precisamente la naturaleza del problema en discusión la que selecciona a los actores que promueven y participan en el decision making. Algunos resultan atraídos directamente; otros, en cambio, son inducidos, estimulados u obligados a quedarse al margen o a permanecer excluidos totalmente. Quien participa en el proceso decisional lo hace por objetivos propios y específicos, sea en relación a las cuestiones a decidir, sea respecto al proceso en sí mismo. Y para perseguir estos objetivos moviliza los recursos que posee o que puede procurarse para esta ocasión. Así, combinando el tipo de elementos que intervienen en el juego, los objetivos de cada actor y los recursos de que dispone se forma el tejido de interacciones del que derivan los resultados del proceso decisional, entendiendo por tales las consecuencias observables del mismo (cuadro 1).

CuAdro 1. ESQUEMA DEL PROCESO DECISIONAL

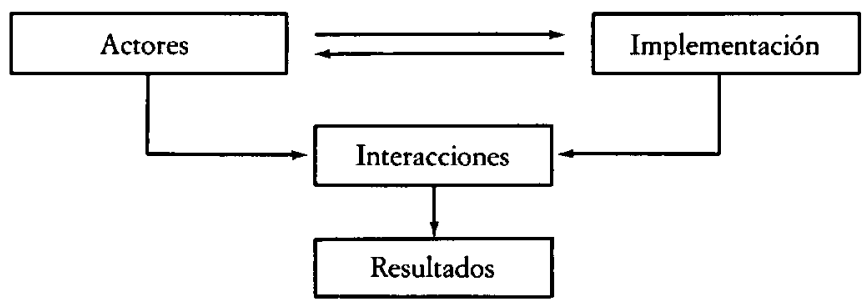

Un examen puntual de los actores que han tomado parte en los procesos decisionales relativos a los estadios del «Mundial 90» es, por tanto, un paso necesario y preliminar para llegar a enfocar las doce expe- 
riencias de gobierno local, estudiadas bajo una interpretación de conjunto. Una descripción preliminar de las múltiples «subjetividades» que han dado cuerpo a «Italia $90 »$ es lo que precisamente me propongo en este artículo. Sin embargo, aunque parezca un cometido expositivo banal, las vicisitudes de que debemos ocuparnos constituyen una tarea, en todo caso, interesante.

No se trata de historias de «administración común». Más bien su interés reside, precisamente, en el presupuesto estratégico que en ellas se percibe, o sea, movilizar y hacer funcionar, en régimen de stress, una serie compleja de estructuras públicas y privadas, de competencias administrativas y empresariales, de responsabilidades políticas e institucionales. $Y$ esto mediante la imposición de lógicas, modalidades $e$ instancias decisionales a menudo inusuales, a veces nuevas $y$, con frecuencia, reveladoras de futuribles escenarios político-administrativos del gobierno local en Italia.

Aquí sólo se trata determinar y dar a conocer los titulares y reservas de los «equipos» que han jugado el «partido» de los estadios en los campos de los distintos sistemas político-administrativos locales implicados en la operación «Italia 90». Para ello, procuraré analizar los supuestos subjetivos de este extraordinario case study sobre el gobierno local italiano y sobre las condiciones de posible implementación de una gran política pública nacional confiada a la «periferia» del sistema político.

\section{EL FUTBOL COMO POLICY AREA (1)}

Este caso pertenece a un conjunto de problemas y políticas tan evidentes y complicados como ignorados por la reflexión y el análisis de la ciencia política y la ciencia de la Administración, aunque podría decirse por las ciencias sociales en general. En una palabra, el fútbol nunca ha sido tomado muy en serio por los estudiosos de sistemas políticos y por los que han reflexionado, en particular, sobre el sistema político italiano. Un vacío que resume, en sí mismo, cierto formalismo politológico italiano, el temor a ocuparse de temas no aseguradores de rentabilidad académica, algo de esnobismo intelectual hacia fenómenos confinados apresuradamente en los márgenes folklóricos de las dinámicas sistemáticas y cierto pudor por lo que despierta impulsos y aficiones a menudo compartidos, pero considerados poco edificantes por el status y la imagen científica de quien ocupa una cátedra universitaria.

(1) Tomo prestado de Theodore J. LowI como es evidente, la denominación de policy area, aunque en este caso sea más para evocar un campo semántico de aproximación que el cuadro conceptual e interpretativo propiamente lowiano. Véase, T. J. LowI, «American Business, Public, Policy, Case Studies and Political Theories», en World Politics, XVI, 1964, pp. 677.715. 
Es, en realidad, un vacío relevante. En efecto, el fútbol no es sólo aquel mundo de pasiones e intereses que todos los días justifica los titulares fanfarrones de sus periódicos, el aliento de sus comentaristas o el pathos de la charla deportiva en la cafetería o en la televisión. Ni es sólo aquel inmenso psicodrama colectivo que se materializa cada semana en ritos religiosos de masa, con propios dogmas y reglas comunitarias. El fútbol tampoco es sólo un juguete del capitalismo italiano más aristocrático. $\mathrm{O}$ sólo un vehículo de promoción del empresario provincial más dinámico y trepador. O sólo el motor impetuoso y multiplicador de la producción televisiva y del conglomerado empresarial, público y privado, relacionados con él. En realidad, el fútbol es todo esto, pero también algo más complejo y sofisticado, como todo el mundo sabe. Mejor dicho, como todo el mundo advierte, pues la crítica deportiva, para dignificarse como «prensa especializada», prefiere ofrecer la imagen de planeta autónomo, con su peculiar naturaleza. Naturaleza a la que tal vez hay que defender contra la intromisión de la sociedad y las injerencias del Estado, las instrumentalizaciones de la política y los condicionamientos de la economía, pero, en todo caso, un mundo aparte, con una fuerza propia, con valores y códigos de comportamiento propios.

Lo cierto es que los signos de la separación no faltan e incluso son enfatizados por la praxis y los estilos profesionales propios de aquel mundo.

El fútbol es una gran y definida community en la que se cruzan y conviven, en una intensa relación simbiótica, una múltiple gama de actividades deportivas, económico-empresariales, comunicativas. El alma de la educación deportiva y del gran business espectacular/televisivo cohabitan en una forma de sinergia. El fútbol-deporte no puede vivir y desarrollarse si no es promovido, financiado y finalizado por el fútbolespectáculo. El fútbol-espectáculo, a su vez, necesita del fútbol-práctica deportiva de masa, sea para reclutar siempre nuevos y «frescos» actores para sus espectáculos, sea, sobre todo, para alimentar, desde la niñez, aquellas fantasías individuales e identificaciones colectivas con que el espectador no se contentará con asistir al espectáculo futbolístico, sino que querrá participar en él en primera persona, precisamente como aficionado, compartiendo con la mayor emotividad el drama que se cumple o representa en el campo.

Sobre esta doble alma el fútbol pretende y defiende su propia y plena soberanía. Por tanto, tiene una forma de gobierno propia y arenas propias donde hallan representación y mediación los intereses individuales y colectivos que componen su específico conjunto social y su propio ambiente cultural. Además, sabe proveerse de élites propias, de agentes «políticos» colectivos (... la asociación de los equipos de clubes profesionales, el sindicato de futbolistas) y de mayorías y oposicio- 
nes que actúan en relación a quien conduce la estructura de asociación en su conjunto y en sus distintas formas de agregación. Aún más, a las reglas del Estado que afectan a su organización jurídica formal el fútbol añade normas y praxis convencionales con las que garantiza su autogobierno y la composición de sus situaciones de conflicto interno. Resumiendo, el fútbol, además de un ordenamiento jurídico «privado», es también un «sistema político» autónomo.

Pero también es verdad que el mundo del fútbol vive en una relación de mutua y porosa conexión funcional con el sistema político-administrativo y con el sistema de las empresas. No sólo en la acepción. más antigua y tradicional: el apoyo público y privado al asociacionismo deportivo de masas, donde políticas del Estado de legitimación social y políticas electorales de clientelismo se cruzan con estrategias empresariales de autoidentificación territorial y municipal con determinadas comunidades locales, a las que ciertos grupos económicos ofrecen un sucedáneo de identidad colectiva, a veces frágil y contingente, pero otras veces incorruptible por agentes políticos o culturales, ajenos al juego del balompié y del equipo preferido, sino que también la conexión entre fútbol, sistema político-administrativo y mundo de las empresas se verifica en un sentido más actual y definido.

El fútbol profesional es el mayor entertainment de masas italiano; no sólo alimenta el financiamiento de todo el deporte nacional y de sus infraestructuras, sino que pone en circulación recursos económicos que sustentan todo el mercado de la producción televisiva y de la comunicación de masas, con efectos de penetración en sectores impulsores del comercio internacional de bienes y servicios. Pero el fútbl es también un gran y permanente, si no el único, «animador de masas» (2) de nuestro país (además de una parte considerable de dos continentes). Con este papel estimula también la formación, acumulación y empleo de una ingente cantidad de ayudas, apoyos o sustentos para los que, profesional o institucionalmente, se ocupan de política y de consenso. $\mathrm{O}$ sea, el espectáculo futbolístico proporciona recursos útiles a quien opera en las arenas de la política nacional y local, a quien se empeña en el conflicto entre los partidos y en los partidos y a quien actúa para la formación e implementación de las políticas públicas.

Este múltiple papel político del fútbol hace que los empresarios, proveedores y mediadores del espectáculo futbolístico, actúen mutuamente, intensamente, con las élites políticas del Gobierno y del Parlamento y con las élites de las burocracias de la Administración central y de los entes más próximos al asociacionismo futbolístico. Es una in-

(2) Para citar a G. VINNA1, Fussballsports als Ideologie, Frankurt am Main, Europaische Verlagsanstalt, 1970 , p. 9, quien opina que «sólo el deporte parece estimular a las masas de una forma verdaderamente potente». 
teracción que a veces llega al enlace o a la superposición de cargos políticos y cargos futbolísticos en las mismas personas, o que puede expresarse en un estrecho parentesco de funciones propias del uno o del otro mundo. En la base de esta unión de funciones futbolísticas y funciones políticas existe una relación fundamental de intercambio.

Por una parte, la política garantiza el más libre y faraónico desarrollo del fútbol-espectáculo y de sus televisivas sinergias publicitarias y empresariales.

Por otro lado, el fútbol, aun en su «olímpica» independencia, ofrece al ministro, al parlamentario, al administrador local o regional, así como al dirigente del partido o al alcalde o al presidente del Consejo o de la República, la manera más sencilla y gratuita, pero también más ampulosa y enfática, de demostrar que él también, al fin y al cabo, es un aficionado, por tanto, un verdadero y auténtico ciudadano común (3).

Es decir, en el fútbol el actor político encuentra la oportunidad para consolidar simpatías y conformidades culturales y afectivas que le acercan emotivamente a sus representantes, gobernados o administrados. Un fertilizante óptimo para un abigarrado pero extenso apoyo social hacia la clase política en su conjunto, o —según las circunstancias - en un sentido sucedáneo, o una simbólica reserva, acaso más eficaz y duradera que otras, especialmente a falta de fuertes competencias en el campo de las ideologías políticas o civiles.

Además, el fútbol pone sobre el platillo de la balanza también otras preciosas oportunidades para la política.

En primer lugar, la posibilidad de alimentar y orientar — con los instrumentos legislativos, la decisión administrativa y la hacienda pública - políticas que repartan recursos e imágenes ligadas a la eficiencia del espectáculo futbolístico, a su vivero atlético paraprofesional y al desarrollo de las técnicas de las instalaciones e infraestructuras civiles relacionadas con todo esto. Por tanto, promoción de formas de asociación, formación profesional e industria de la construcción dedicada al fútbol vienen a juntarse, ofreciéndose impulso recíproco.

En segundo lugar, el fútbol ofrece a los agentes políticos oportunidades adicionales de promoción y de carrera política. Por consiguiente, a los partidos la posibilidad de darse ulteriores articulaciones «organizadoras» en las redes del asociacionismo futbolístico y de sus instancias de dirección y gobierno. No están tanto en juego los usuales fenómenos de repartición de cargos públicos y privados, sino más bien algunas específicas propensiones en los mayores partidos del gobierno

(3) Sin querer por ello restarle nada a la espontaneidad con que el presidente de la República más amado de los italianos, Sandro Pertini, se convirtió en la imagen misma de un pueblo de tiffosi la noche madrileña en la que Italia conquistó su tercer título mundial. 
de disfrutar de la gran audiencia que el espectáculo deportivo garantiza, procurando adecuar a las necesidades su «sistema de poder» (4) (por otra parte, sin abandonar los buenos favores de aquel «centralismo deportivo» que siempre ha puesto en común el activismo organizador de los mayores partidos, sea de la mayoría o de la oposición).

En este marco, la élite del espectáculo futbolístico ve que se le reconoce una señalada «función social», más allá de algún doctorado bonoris causa que ciertas universidades italianas puedan otorgar a los indómitos dirigentes de ciertos equipos de fútbol (5). Lo que apunta a que el espectáculo futbolístico llega a ser una variable estratégica en la combinación de las demandas, necesidades, oportunidades que componen los problemas de gobierno de las áreas metropolitanas más importantes de Italia. Mientras que los empresarios que emplean fondos en el espectáculo futbolístico consiguen, de esta relación de intercambio entre fútbol y política, múltiples oportunidades para las respectivas estrategias empresariales. Se trata, obviamente, de recursos adicionales; cada miembro de la leadership futbolística de tipo empresarial ya tiene otros recursos fuera del fútbol. Pero para el agente económico que quiere actuar también en el mercado político y en el de la comunicación las oportunidades procedentes del espectáculo futbolístico tienen un gran valor intrínseco, aunque sólo sea integrativo o de apoyo. Un valor destinado a autoalimentarse cuanto más el fútbol se vea favorecido, estimulado, legitimado, halagado por la clase política y la empresarial y cuanto más los políticos y empresarios - de forma directa o indirecta- sigan empleando en el mismo sus respectivas «responsabilidades» públicas.

En esta perspectiva, el fútbol puede ser todo menos un «mundo» autónomo. Se configura, en cambio, como una articulación orgánica del sistema político. Un subsistema dotado de una penetrante capacidad de hacer coincidir el conjunto de las componentes estructurales e institucionales, centrales y periféricas del sistema mayor. Y capaz de desplazarse transversalmente a lo largo de su funcionamiento, penetrando en las fuentes de la legitimación y de la agregación social, en los lugares y procesos de las políticas públicas, en la misma racionalidad de la actividad política y la económica.

Prueba y consecuencia de esta múltiple ósmosis entre fútbol, política y estrategias de empresa es el estado particular de la gestión fut-

(4) Como denominaba años atrás Antonio BALDASSARRE a ese «conjunto de asociaciones o de entes (incluso públicos) hegemonizados por un partido», el cual, «a través del mismo», gestiona «los recursos políticos de esos aparatos como si fueran suyos». A. BALDASSARRE, «Los grupos parlamentarios comunistas», en M. ILARDI y A. ACCORNERO, El Partido Comunista Italiano. Estructura e bistoria de la organización, 1921-1979, Anales de la Fundación Giacomo Feltrinelli, XXI, 1981, p. 448.

(5) La cita hace referencia a la distinción otorgada por la Universidad de Urbino en 1989 a Constantino Rozzi, presidente del Ascoli, F. C., por sus excepcionales méritos «humanos». 
bolística. A pesar de sus dimensiones económicas, el fútbol-espectáculo parece que aún no se haya dotado de una particular y definida clase dirigente, distinta y autónoma de aquella mezcla de intereses e impulsos, de aquella verdadera heterogénesis de los fines que está en la base del fenómeno futbolístico y que, precisamente, lo hace una variable transversal del sistema político y del mundo de los negocios. Entendámonos; si existe un ambiente en el que el uso de la palabra manager parece de rigor y bien envuelta entre los signos y oropeles de la modernidad, éste es, sin duda, el fútbol-espectáculo. Pero el management futbolístico parece carecer de firmes y adecuados anclajes formativos y profesionales autónomos. Por lo visto, la propia operación «Italia 90» tuvo que tomar a los managers en préstamo de los sectores empresariales específicos comprometidos en el patrocinio de la manifestación.

Naturalmente, las excepciones existen y están produciendo efectos imitativos notables, por lo menos a nivel de los equipos de club. Pero son experiencias tan enfatizadas que testimonian su naturaleza de excepciones. Normalmente, el gestor diario del espectáculo futbolístico no tiene hasta ahora un estatuto profesional propio y definido, congruente con la naturaleza específica del producto que debe comercializar. El know how que hoy en día expresa el management futbolístico es la habilidad mediadora entre las varias atenciones, las múltiples racionalidades y las intensas pasiones que envuelven y componen el espectáculo futbolístico. Pero las gestiona y orienta como se manifiestan: logra ampliar su impacto y efectos multiplicativos, pero no llega a filtrarlas y dirigirlas realmente.

En suma, es un manager un poco artesano, un poco especulador. Cabalga con gran habilidad en lo que ORTEGA y GASSET hubiera llamado las «circunstancias», pero sin metas o estrategias de largo alcance. Y a pesar de los símbolos de su renta y de su estatus, y el asfixiante tamborileo de los medios de comunicación sobre sus indiscreciones e iniciativas, su talento recuerda más el tópico del «italiano» listo y oportunista que el rigor del master adquirido en la «Bocconi» (6).

No sé si éstas son sólo cavilaciones de quien, ayuno de prensa deportiva, se ha propinado una overdose de ella. Sin embargo - aun sin colocarme entre los que rezan al buen Dios que los libre del fútbol y de sus aficionados, ni entre los que lo observan con afectada suficiencia-, la impresión antes formulada me parece plausible. Y, en todo caso, es un buen estímulo para ver si la «extraordinaria necesidad y urgencia» del campeonato mundial del noventa habrá proporcionado o no al espectáculo futbolístico profesionales propios y autónomos.

(6) El autor se refiere a la Universidad Bocconi de Milán, famosa por su escuela de ma. nagement (nota del editor). 
Pero son más bien otras las oportunidades de análisis y reflexión ofrecidas por «Italia 90». En efecto, es el cuadro entero de las temáticas, antes mencionadas lo que entra en juego. Los procesos decisionales para poner a punto los doce estadios del Mundial permiten observar las expresiones reales de la intesa simbiosis entre fútbol, políticas públicas y políticas de empresa. Hay que individualizar los múltiples actores que participan en aquel vínculo intenso. Hay que tomar y examinar las lógicas que los mueven y que presiden sus interacciones. $\mathrm{Y}$ hay que ver si las vicisitudes de los estadios han permitido que emergiera la acción de un conjunto «político-futbolístico» compuesto por estrategias integradas y por relaciones propias de una duradera alianza político-empresarial.

Esta última podría ser una hipótesis plausible. Mucha prensa la ha dejado entrever. Y el mismo legislador estatal parece haber prefigurado o sancionado (7) tal conglomerado de intereses empresariales y políticos, que además resultaría coherente con esa línea transversal del fútbol a la que antes me he referido. Pero quiero advertir rápidamente que tal hipótesis no se puede apoyar con los elementos que tenemos.

En esta perspectiva, por tanto, es indispensable una descripción de aquellos sectores en su configuración formal y funcional, y en el papel desempeñado en aquellos procesos, aunque desde un punto de vista limitado: el del gobierno local y de las políticas de reforma urbana. En efecto, procuraré observar qué actores del sistema político-administrativo local participan en los procesos decisionales relativas al Mundial del fútbol, atendiendo a cómo desempeñan su papel «estatutario» en sus respectivas ciudades. Y precisamente por esta previa necesidad de claridad, voy a limitar el análisis a un punto de observación elemental, enfocando sólo el centro de cada proceso de decisión local y considerando a los actores que en él gravitan, sobre la base de la fuente institucional de su legitimación.

Por tanto, se examinarán:

- los actores políticos que operan en las Administraciones locales y regionales;

- los actores burocráticos de las Administraciones del Estado, de las regiones, municipalidades o provincias, de la magistratura ordinaria o administrativa o de las instituciones de control estatales o regionales;

- los expertos en cuanto proyectistas externos o internos en las Administraciones encargadas de los problemas derivados de la adecuación de los estadios;

(7) Volveré a ello más adelante. 
- los intereses representados por las empresas en competencia por las obras o encargadas de las mismas, y por las sociedades de fútbol cuyos campos han sido elegidos para la preparación de «Italia 90».

Quedará fuera de esta exploración una larga serie de actores colectivos de gran importancia y que, con diversa capacidad de influencia, han girado alrededor de los ejes cruciales de los procesos decisionales: secciones sindicales de sector o que agregan instancias más generales, grupos de interés nacionales o locales, intereses difusos con demandas colectivas monotemáticas de base territorial, el público de los media locales y nacionales, deportivos y no deportivos, y los «observadores» más cercanos al policy making (y la lista podría ser aún más extensa).

Procuraré, en cambio, no pasar por alto a los actores operantes o que se hallen en las estructuras de la polity local (8), aunque pertenecientes a un «nivel» distinto de gobierno..., teniendo en cuenta aún aquella «definición» de «sujetos, procedimientos y modalidad de financiamiento» (9) con que Gobierno y Parlamento, entre los años ochenta y siete y ochenta y nueve, han pensado garantizar la rapidez y eficacia de las decisiones de las autoridades centrales y de las Administraciones locales, precisamente promoviendo una interacción «transversal» capaz de eludir, si no de limitar, los problemas institucionales entre niveles «altos» y «bajos» del sistema político-administrativo general. Considerando para tal fin una legislación específica sobre el campeonato de fútbol, consiguientes disposiciones administrativas $\mathrm{y}$, sobre todo, activando adecuados procesos de regulación político-administrativa (10).

\section{LOS ACTORES POLITICO-ADMINISTRATIVOS}

El conjunto de los doce casos examinados confirma empíricamente una premisa metodológica ya habitual en el análisis de las políticas públicas que atañen a los gobiernos locales, sobre todo cuando están en discusión el territorio, las estructuras y el paisaje de la ciudad y de la metrópoli (11). O sea: las instituciones político-administrativas locales

(8) Según la formulación de L. GALLINO, «Policy making in condizioni avverse», en A. BAGNASCO (ed.), La città dopo Ford. Il caso di Torino, Torino, Bollati Boringhieri, 1990, p. 73.

(9) Usando la expresión del Decreto-ley de 3 de enero de 1987, núm. 2, convertido en la Ley 65/1987, de 6 de marzo, que fue la primera disposición normativa destinada a hacer frente a la puesta a punto de las ciudades que debían albergar las pruebas de «Italia 90».

(10) Una «regulación» que recuerda la noción de «regulación social» elaborada por LAN GE y REGINI, «Los intereses y las instituciones: formas de regulación social y políticas públicas», en P. LANGE y M. Regini, Stato e regolazione sociale. Nuove prospettive sul caso italiano, Il Mulino, Bolonia, pp. 9-41.

(11) Véase L. BobBio, B. Dente, P. Fareri y M. Morisi, Metropoli per Progetti, Bolonia, Il Mulino, 1990. Más en general, IRER-Proyecto Milán, Istituzioni e nuovi modelli di Governo 
no expresan - de hecho- una univoca subjetividad propia; son unas «arenas» (12) - y no necesariamente las arenas- del decision making local, en las cuales y por las cuales pasan y actúan recíprocamente los sujetos reales del «poder local» que obran en el tema del Mundial. No están en juego el «Ayuntamiento» o la «Administración local». Son los actores, que atraviesan y empapan al uno y a la otra, los que existen y actúan.

Y existen y cuentan su distinta legitimación, su individualidad operativa, sus funciones de utilidad subjetivas y organizadoras, sus propensiones culturales y subculturales, sus accesos a otras instancias de gobierno y sus vínculos con los intereses y con el partido. $\mathrm{Y}$ es con tales connotaciones y atributos que estos mismos actores -y sólo ellos-constituyen materialmente el funcionamiento de las instituciones del gobierno local y la única real subjetividad que se puede atribuir a ellas.

Es, sin duda, una premisa obvia y banal, pero que nuestro case study no solamente confirma en el plano de la documentación empíri$\mathrm{ca}$, sino que incluso enfatiza.

\subsection{El administrador local}

Las instituciones del gobierno local a las que me refiero son solamente las Administraciones municipales de las ciudades interesadas. Los demás entes territoriales, como regiones y provincias, no aparecen en el decision making. En particular las regiones casi nunca entran en juego, y en los casos muy raros en que esto sucede, la participación de las regiones se verifica en términos irrelevantes o muy marginales con respecto a la dinámica de cada proceso decisional; a veces para facilitar el desbloqueo de impasses causados por órganos de control propio, a veces para financiar obras complementarias.

Es lo que ha ocurrido en Palermo, por ejemplo, donde el presidente de la región se hizo cargo de una acción de mediación entre el Consejo Regional de los Bienes Culturales y Ambientales y la Administra-

urbano, Milán, Franco Angeli, 1989. Para una racionalización en çlave prescriptiva del tema, M. GABBI y A. TERZI, Assessore cercasi. Gli amministratori locali tra etica e management, Milán, Sipiel, 1990.

(12) Uso la expresión en la forma más clásica propia del análisis de políticas públicas que ha proporcionado T. Low en el texto citado más arriba, y en sus obras Decision Making vs. Policy Making: toward an antidote for technocracy, en PAR, 1970, pp. 314-325; también en Four systems of policy, politics and choice, en PAR, 1972, pp. 298-310. Es significativa la asonancia conceptual de la noción lowiana de «arena», tan intrínsecamente ligada a la noción de government (y de rule), como subraya M. CALISE, «Organizzare le politiche: arene di partito e arene amministrative a Napoli, 1975-1983», en Democrazia e Diritto, 1987, p. 217, con la noción iuspublicista de «función de sector» elaborada por M. S. Giannin, Diritlo Pubblico dell'economia, Bolonia, II Mulino, 1977, pp. 239-240 y cap. IX. 
ción municipal, acerca de la tutela de las partes «histórico-artísticas» del estadio palermitano conocido como la «Favorita»; o, después, cuando al mismo presidente de la Junta regional ha amenazado al Ayuntamiento con nombrar un comisario regional ad acta para superar las indecisiones sobre el sistema de adjudicación de las obras de finalización de la instalación. Aunque también es verdad que el caso de Palermo es una excepción por el papel peculiar de su Administración regional con autonomía especial y con el peso de derecho y de hecho de su región en el sistema político local y en las interacciones con la Administración y el Gobierno central. Sin embargo, lo que se evidencia es que tampoco esta región desempeñó un papel decisional estratégico o de coordinador supramunicipal capaz de influir en las opciones de los entes locales sobre el cómo prepararse ante el feliz «acontecimiento».

No debe asombrar la marginación regional. Las regiones tienen una arraigada y notoria dificultad para intervenir, de una forma significativa, en los procesos decisionales que se refieren a las políticas urbanas de sus capitales (13). Pero en el caso de los estadios existe también el problema de un preciso diseño normativo de las relaciones entre los distintos niveles de gobierno imaginados por el legislador estatal, el cual ha predispuesto los recursos y la instrumentación organizadora para la celebración del campeonato del mundo, pasando por alto la instancia regional, precisamente como instancia de gobierno.

Es lo que ha sucedido con el Decreto-ley de 3 de enero de 1987, número 2, después modificado en la Ley núm. 65, de 6 de marzo de 1987 (la disposición que financia, precisamente, los encargos para los nuevos y viejos estadios). Las operaciones relacionadas con los estadios del Mundial - y con aquellas instalaciones deportivas ajenas al gran espectáculo futbolístico (previstas para compensar simbólicamente unos rubores no bien disimulados del legislador, que se introduce en la operación mundial con algún pudor inicial) - deben ser «concertadas» entre el Ministerio de Turismo y de Espectáculos, el CONI, las comisiones parlamentarias competentes, la Dirección General de la Caja de Depósitos y Préstamos, la presidencia del Instituto para el Crédito Deportivo, los Ayuntamientos y sus consorcios, pero no con las regiones (excepto una serie de consultas, con que las regiones aparecen conjuntamente con las provincias autónomas de Trento y Bolzano, el Anci y la Unión italiana de provincias). Por otra parte, la misma disposición legislativa llega a la Gazzetta Ufficiale después de intensas relaciones directas entre CONI, COL, Ministerio de Turismo y Administraciones municipales, y la misma elección estratégica de las doce

(13) Véase el trabajo de BOBBIO, DENTE, FARER y MORISI citado más arriba, en el que ello ha sido objeto de investigaciones empíricas. 
ciudades se efectúa sin ninguna visible «interferencia» regional. Donde ha sido necesario, las mismas Administraciones municipales han tratado de conseguir apoyos para sus respectivas candidaturas, sea dentro del marco gubernamental y de sus ámbitos territoriales, sea - más habitualmente - en las comisiones parlamentarias. Desde esta perspectiva, tampoco asombra la siguiente elección del legislador, siempre en el asunto del Mundial 90. La Ley 205, de 29 de mayo de 1989, convierte en Ley (después de una triple deliberación) el Decreto para las tan esperadas infraestructuras que deberían sancionar la subjetiva trascendencia del Mundial para el bien común. Para este fin, la Ley-después de una, aún más intensa, experiencia de interacción directa entre administradores municipales y Ministerios competentes, proseguida después en las comisiones parlamentarias competentes- legitima y racionaliza la negociación directa entre municipalidades, Gobierno y Administraciones estatales, excluyendo formas o intervenciones de mediación o de coordinación intermedia. Así, la Ley establece que, para las obras de los entes locales, es el alcalde quien convoca la «conferencia de servicios» en la que «participan todos los representantes de las Administraciones del Estado y de los entes directamente obligados a adoptar acuerdos, así como a expedir dictámenes, autorizaciones, aprobaciones, permisos contemplados por las leyes estatales y regionales» [art. 2.a).1. ${ }^{\circ}$ ], y cuya decisión «tomada por unanimidad» está confia$\mathrm{da}$, por ello, a un conjunto de responsabilidades y legitimaciones politicas y burocráticas formalmente impulsadas a mezclarse y a corresponsabilizarse (así como a desresponsabilizarse) recíprocamente. Mientras que «a todos los efectos, los acuerdos, dictámenes, autorizaciones, aprobaciones, permisos considerados por las leyes estatales y regionales» son sustituidos por el placet unánime que también puede variar e integrar la instrumentación urbanística previa, las normas de la planificación territorial y la relativa a los aeropuertos «... sin necesidad de ulteriores trámites» [art. 2.a).3..$^{\circ}$.

Otro elemento de reflexión está en el hecho de que los administradores municipales de nuestras doce ciudades son precisamente sus «administradores», o sea, actores «político-administrativos» muy poco vinculados o condicionados por sus respectivos partidos. La influencia del partido de los «administradores» no desempeña, de hecho, un papel autónomo y discriminatorio en relación a su comportamiento. Esto se puede comprobar en términos sea de objetivos, proyectos, negocios; sea, sobre todo, en relación al control y coordinación de la acción de los administradores directamente implicados en los procesos decisionales.

La afirmación parece desmentida por muchas excepciones durante el desarrollo de ciertos procesos decisionales, donde, en específicos momentos cruciales, la conducta de los administradores respeta, cierta- 
mente, lógicas partidarias y no preocupaciones sustantivas. Pensamos en Roma, donde el proceso decisional parece expuesto constantemente a la fragilidad y a las tensiones de los acuerdos y discrepancias de las coaliciones y de la crisis de Gobierno, con la circunstancia agravante de un conflicto entre partidos, corrientes y facciones fuertemente atravesado por las coyunturas del «marco político» nacional y por sus rivalidades internas. Y pensamos también, en un ejemplo mucho más propicio para los especialistas de la «partidocracia», en la experiencia de Turín, donde en todas las decisiones cruciales, actores y lógicas peculiares de partido sustituyen las competencias burocráticas; unos y otros, decididos a conservar un control pleno en todos los aspectos, aun el más mínimo, de lo que deba decidirse. Por tanto, aun las cuestiones más técnicas van a parar a la mesa de la mediación política, con un gobierno municipal que sigue atentamente la discusión sobre el diseño del nuevo estadio o sobre las cláusulas de una caución bancaria. Dos ejemplos servirán. El «informe técnico» para la convocatoria es elaborado personalmente por el concejal para el deporte, mientras el ingeniero-jefe del Ayuntamiento rechaza suscribir ese mismo documento. La comisión decisora para otorgar la concesión de construcción (y gestión) de la nueva instalación se compone solamente de los representantes de los siete partidos en el gobierno municipal, dado el carácter «político» de la elección del concesionario en un concurso en el que precisamente no debe decidirse sobre «proyectos», sino sobre «constructores».

Pero más allá de las excepciones que se puedan hallar, nuestra afirmación precedente choca con lo que habitualmente se percibe acerca del funcionamiento del «poder local» en Italia.

Nuestra formulación quiere tener un sentido muy preciso y definido, que es el siguiente: en las circunstancias examinadas no se da el caso de que los partidos locales conciban (de forma algo visible) un planteamiento político específico sobre la «digna acogida» del Mundial y sobre las oportunidades conexas con él; empezando por la opción previa: aceptar o no la organización del Mundial. Aunque hombres de partido y, por tanto, sensibles, por cierto, a los equilibrios, disposiciones, coyunturas tácticas y estrategias de las respectivas organizaciones políticas serán, sin embargo, los administradores que se enfrentarán con los nudos políticos del planteamiento y asumirán la negociación con los intereses presentes. Acaso se pueda entrever - pero sólo entrever- un específico rol de los grupos de concejales. Por ejemplo, ésa es la situación de Milán, donde PCI y PRI actuaron, sobre todo, en cuanto grupos de concejales $y$, por tanto, intervinieron como actores unitarios.

El administrador local es, pues, precisamente el administrador de carne y hueso. Un actor fuertemente antropomórfico. Y los procesos 
decisionales relativos a los estadios adquieren en todas partes una connotación «personalista». Por lo cual, tiende a esfumarse la cuestión que habitualmente nos ponemos cuando nos enfrentamos con este género de procesos y, sobre todo, cuando analizamos el comportamiento de estos actores, acerca del prevalecer de lógicas de comportamiento más sustantivas, conexas con el cómo definir y enfrentar los problemas en su efectiva materialidad, o, en cambio, más partidarias, por tanto, más correspondientes a preocupaciones de dependencia o de carrera política o de afiliación a intereses en juego. Por supuesto no desaparecen las lógicas partidarias y las preocupaciones electorales, aún más cuando, como en el caso de «Italia $90 »$, la forzosa conclusión del decision making local coincide con período electoral. Sin embargo, las fuertes preocupaciones de conformidad y fortalecimiento personal en los electorados locales, en las agregaciones de intereses urbanos y en las respectivas conexiones de partido se enlazan con otras racionalidades, múltiples y variadas.

También es claro que el corte fuertemente «personal» de la acción del administrador local que desempeña un papel en los procesos decisionales del Mundial está en correlación estrecha con las características de estos procesos decisionales. Procesos que adquieren la forma de limitados y selectivos ámbitos de interacciones entre cada administrador y los actores representantes de los intereses ajenos a la Administración —en el intento de protegerse de la situación de conflicto (y de la visibilidad) - , política que caracteriza la vida ordinaria de las Administraciones municipales.

Las redes de relaciones entre los actores resultan fuertemente conformadas y predefinidas por las formulaciones obligadas de las cuestiones a decidir (construcción de doce estadios, idóneos para el Mundial, en un plazo determinado e ineludible), por las modalidades de arranque de cada proceso y de su propio desarrollo, alrededor de un circuito decisional «central» dado por el trinomio actor municipal-planteamiento técnico-empresa o planteamiento técnico-empresa-actor municipal.

En ciertas situaciones, esta red es atravesada y conformada por preexistentes y fuertes conexiones político-futbolísticas (como aparecen reconocibles, en cierta manera, en el caso de Milán y en el de Bari), capaces de predefinir los márgenes de propuesta y maniobra del actor administrativo, o incluso la selección del propio interlocutor público entre el personal político-administrativo local.

Contribuye a esta perspectiva de network bien delimitado, la presencia y acción de ciertos administradores-pivot. Son administradores depositarios de amplias y notables representaciones de negocios - explícitas o implícitas- por parte de la Administración de pertenencia. $\mathrm{O}$ bien, son administradores que, por razones propias y con funciones 
de utilidad diferentes, emplean su crédito político y administrativo, poniéndose como parte implicada en los asuntos relativos y, por tanto, como interlocutores necesarios para su desarrollo. Su competencia en administrar el asunto prescinde de la etiqueta formal de su concejalía específica. Si se trata de concejales, a menudo es el «deporte», pero también la «hacienda pública» (Milán), también las «obras públicas» (Génova y Roma), así como las construcciones públicas y privadas (Nápoles). Los concejales así «competentes», en todo caso, tienen unas posturas de autoridad política de partido en sus respectivos grupos gubernamentales, a veces consolidada incluso por vicealcaldías (Florencia y Génova). Los concejales de urbanismo - si no tienen el encargo de atender el asunto estadios/Mundial- desaparecen (ver Florencia).

Los alcaldes sólo en circunstancias específicas se hacen cargo personalmente de los procesos decisionales. En este sentido, el caso límite es Cagliari, cuyo alcalde evita con cuidado todo compromiso real que vaya más allá de sus competencias formales. Palermo es la excepción contraria, donde Orlando es el protagonista político $a b$ initio que extiende a la operación «Mundial» la huella de su new deal administrativo. También Roma, con Giubilo, llega a ser una excepción, con el alcalde de la capital que toma el mando directo de las operaciones. Sin embargo, en conjunto, los alcaldes prefieren para sí mismos un papel de decisores eventuales o de segunda instancia, aun cuando a veces dirimente.

A menudo, el actor que guía la conducta de la Administración local sobre los estadios y que procura orientar el proceso decisional es un «deportista», incluso un aficionado. Tiene un sentir futbolístico propio.

Esta sintonía eventual con la cultura y las razones del balompié puede consentir a las opciones del administrador o a las decisiones que él apoya el pasar indemnes, o incluso afianzadas, en el variar de las coaliciones de gobierno o en el sucederse de mayorías diferentes y en la alternancia de concejales (es el caso de Florencia). Con frecuencia, nuestro protagonista público dispone además de fuertes conexiones con el asociacionismo local o regional (como, por ejemplo, en Bolonia). Pero, sobre todo, son las relaciones que éste puede mantener con el mundo futbolístico propiamente dicho las que ayudan a su capacidad de guiar el proceso o, en todo caso, que sostienen la relevancia de su papel. Y cuando su curriculum no cuenta con tales relaciones, ni puede fundamentar su acción en una previa relación de confianza con el ambiente futbolístico, ese mismo papel resulta problemático y más complejo y conflictivo todo el proceso.

El actor político-administrativo no se preocupa por particulares mejoras de la organización del Ayuntamiento en lo que se refiere a propuestas y decisiones para satisfacer mejor las urgencias de los estadios. 
No faltan excepciones. Es el caso de Roma y de su «comisión especial para el Mundial», donde se reúnen los portavoces concejales de todos los partidos junto con los miembros de las comisiones para obras públicas y urbanismo de la ciudad.

Y también es el caso de Florencia, donde se constituye una comisión mixta, formada por técnicos, administradores locales y funcionarios estatales junto con los representantes de las minorías de concejales, con el fin de asesorar las decisiones municipales sobre los proyectos de reestructuración del estadio. Pero en la totalidad de los casos no se registran peculiares tentativas de innovación organizadora ad boc.

Por otra parte, el dirigente público logra moverse con notable flexibilidad y autonomía respecto a su «ambiente» institucional. Las instituciones municipales entran sólo en situaciones fuertemente conflictivas entre los actores cruciales, especialmente cuando hay que «decidir» sobre las localizaciones o sobre las asignaciones de las obras. $\mathrm{O}$ bien, cuando las cuestiones de los estadios llegan a ser pretexto $\mathrm{u}$ ocasión de pactos entre los miembros de las coaliciones de gobierno. Pero aun en estas circunstancias, difícilmente se supera el perímetro de los gobiernos locales y a los plenos les quedan, de ordinario, funciones de resonancia y ratificación.

También hay episodios de cambios de posiciones en las asambleas municipales, pero allí donde se dan se plantean según iniciativas maduras, no dentro o alrededor de los plenos, sino en las posiciones y relaciones entre los actores más metidos en los procesos decisionales.

\subsection{Burócratas, revisores, magistrados}

Tratamos de esta «familia» de policy makers dentro del estudio más general sobre el actor político-administrativo local. Los procesos decisionales sobre los estadios, en efecto, han movilizado una pluralidad de competencias burocráticas precisamente respecto a cada Administración local implicada en «Italia 90», fuera cual fuera su formal legitimación y la pertinencia institucional de las diversas burocracias interesadas.

Si en este proceso existe y opera un «actor burocrático», éste no es expresión de la burocracia de municipios o regiones. De esta burocracia «territorial», y municipal en particular, se descubren trazas significativas. Se pueden mencionar órganos como el «Servicio de construcciones públicas» y la «Comisión de alta vigilancia» (por ejemplo en Génova) o la aparición esporádica de otros aparatos administrativos locales. Pero la burocracia municipal no forma parte relevante en este proceso. Por otra parte, acaso nos extrañaríamos de lo contrario, pues el asunto de los estadios representaría, en este caso, una clamo- 
rosa excepción en una más general y amplia ausencia de las burocracias locales de los procesos decisionales con fuerte impacto urbanístico y de obra pública. Por tanto, también por lo que se refiere a los estadios hay que constatar cómo el planteamiento no ha encontrado un apoyo específico de propuestas en los despachos municipales, ni ha movilizado específicas competencias técnicas del Ayuntamiento. Nos podríamos preguntar si proyectar «grandes estadios» y obras similares sea una pretensión realista para una Administración municipal, aunque se trate de una de gran dimensión. Pero también nos podríamos preguntar si no sería imaginable, al menos una capacidad municipal «de respuesta» con respecto al planteamiento privado.

Es una ausencia que los mismos burócratas han confirmado personalmente casi en todas partes. Acaso en Verona se pueda registrar una parcial excepción. En los demás casos, las peculiaridades de planteamientos de las obras, la predefinición de los criterios y de los estándares técnicos por parte de una authority ajena a las Administraciones (el COL), el rol crucial y autónomo de la expertise arquitectónica privada, la legitimada «privatización» de la asignación de las obras, el uso frecuente de la concesión, los partidos que asumen las competencias burocráticas en las circunstancias de mayor conflicto..., todos son factores que han favorecido la sistemática marginación de la burocracia municipal. Y además han evidenciado, una vez más, su inadecuación estructural para un rol efectivo en las grandes operaciones de renovación urbana. Sin que, por otra parte, el administrador local se queje para nada, excepto cuando pide mayor eficiencia a «sus» oficinas para un adecuado apoyo de conocimientos a sus tesis, o sea, una cobertura técnica, y preferentemente a posteriori. Y también en el caso de los estadios parece ser ésta la labor que se encomendó a dichas oficinas.

Bastante más significativo ha sido el peso de ciertos órganos periféricos de la Administración estatal. En primer lugar, los órganos encargados de la tutela de los bienes culturales y ambientales. Son administraciones que, en más de un caso, han dejado una profunda huella en los procesos decisionales y en las selecciones de mérito. Con fuertes implicaciones en los desarrollos de los proyectos, en los tiempos y, a veces, en las propias alternativas en juego: construir un nuevo estadio más bien que reestructurar uno ya existente, ubicar la instalación en un área determinada o en las antípodas urbanísticas de otra. Por supuesto, se trata de consecuencias ni objetivas ni inevitables. Son los varios actores en juego los que, interpretándolos según sus respectivos objetivos, han podido aprovecharse fácilmente de los pronunciamientos de esos órganos haciendo relevante, en todo caso, su impacto en los procesos decisionales.

Algún que otro ejemplo. En Turín, la superintendencia para los bienes ambientales y arquitectónicos de Piamonte decide catalogar el vie- 
jo estadio en cuanto «... excepcional testimonio de arquitectura racionalista en el campo de las instalaciones deportivas» dada «la coherencia y la unidad de las soluciones arquitectónicas adoptadas», ofreciendo una oportunidad esencial a los detractores de cada hipótesis de reestructuración, así como de demolición de la vieja instalación y favoreciendo un apoyo precioso a los partidarios de una instalación nueva, aun después de doce meses de discusión sobre un proyecto de reestructuración.

La superintendencia de Bolonia adopta aptitudes análogas a las de Turín, pero produce efectos decisionales opuestos. Cataloga el viejo estadio Dall'Ara, en 1986, en cuanto obra arquitectónica con más de cincuenta años, pero no apoya las argumentaciones de los que quisieran un estadio nuevo, sino que más bien favorece la reestructuración de la vieja instalación. Así, los diez mil millones proporcionados por el Instituto de Crédito Deportivo para la reestructuración quedan monopolizados enteramente por las obras establecidas por la superintendencia. $\mathrm{Y}$ posibles alternativas para albergar el Mundial acaban siendo perjudicadas.

En Palermo, la superintendencia para los monumentos suspende su juicio sobre el proyecto de reestructuración del estadio La Favorita pasando el encargo al Consejo Regional de los Bienes Culturales y Ambientales. Este detiene todo el proceso durante un semestre - hasta despertar el interés de la magistratura por el retraso de los tiempos de procedimiento- observando en el proyecto que la Administración está a punto de realizar el deterioro de la parte frontal de la vieja instalación -hasta entonces de insospechado valor histórico-arquitectónico- y su incompatibilidad con el sky line de Monte Pellegrino. De aquí una profunda revisión del proyecto mismo. También en Florencia lo que perjudica las soluciones de los proyectos sobre que se desarrollaría el proceso decisional es un preexistente vínculo históricoartístico. En Roma será el propio ministro de Bienes Culturales quien tomará partido directamente - con un telegrama a las autoridades deportivas competentes, regularmente comunicado a la prensa- en defensa del escenario de Monte Mario, contra el impacto ambiental del proyecto para cubrir el Olímpico. Las obras se suspenden y será necesario un nuevo proyecto alternativo de cubierta, no obstante el pleno acuerdo del Ministerio de Turismo acerca de la solución impugnada. Una casuística precursora de consecuencias menores sobre los planteamientos, pero no menos relevantes sobre los procesos decisionales, ha sido alimentada por las «comisiones provinciales de vigilancia sobre los locales de espectáculo público». El rol que han tenido estos órganos en los doce procesos demuestra que se ha tratado de burocracias que tutelan con cuidado y determinación su autonomía con respecto a la política, casi enarbolando gastadas banderas weberianas sobre la «legalidad» y «racionalidad» de la Administración. 
Por supuesto, mirando con más cuidado cada situación, se descubrirían aspectos acaso menos dignificantes.

Sin duda se trata de verdaderos e importantes actores del policy making local, que actúan recíproca e intensamente con específicos actores nacionales y que exigen mantener su rol como ineludible. Quieren ofrecerse como un «filtro» necesario para quien decide en el sector público y para la Administración local en particular, en su conexión con el proyectista, con la empresa y con el ambiente futbolístico directamente interesado. Y a menudo estos actores obtienen y ejercen ese rol, que los convierte en verdaderos policy makers.

Por otra parte, los actores político-administrativos (pero también los proyectistas) parecen enfrentarse a esta reivindicación burocrática con poca atención y cierta superficialidad.

El caso de Turín es verdaderamente un ejemplo óptimo y presenta motivos de amplia y posible generalización. Durante todo un año se elabora un proyecto ejecutivo para la reestructuración del viejo estadio. Nadie de la Administración turinesa se da cuenta de que en Italia está vigente una Ley que ordena la obligatoriedad del acuerdo de las autoridades de tutela sobre todos los bienes públicos con más de cincuenta años. De ahí la intervención de la superintendencia turinesa, claramente intolerante por su implicación en el último momento y ante una decisión políticamente ya definida. Si no fuera suficiente, la Administración municipal consideró que la disposición de aquella oficina «periférica» del Estado se podía fácilmente superar vía el Ministerio competente (que puntualmente confirmó el aviso de su oficina descentralizada). Exactamente eso fue lo que sucedió cuando se recurrió al Ministerio del Interior contra las disposiciones de la «comisión provincial de vigilancia sobre los locales de espectáculo público» acerca de la seguridad del viejo estadio por reestructurar. Se pidió alguna derogación «romana», pero todo fue en vano. Hasta que el concejal para el deporte tuvo que acceder a negociar con el Ministerio de Bienes Culturales una hipótesis mucho más «tenue» de reestructuración.

Es evidente que no estoy aludiendo a un fenómeno nuevo en el ámbito político-administrativo.

Se trata de episodios que ponen en común el asunto del Mundial con cualquier historia de renovación intensa o transformación urbana en ciudades o metrópolis italianas. Es habitual ya en todas partes el conflicto entre poderes político-administrativos y competencias burocráticas, sobre todo en las temáticas ambientales, sanitarias, histórico-artísticas.

Lo que más bien el Mundial parece evidenciar, y claramente, es que el rol activo y condicionante - si no decisivo - reivindicado por cierta burocracia estatal se conexiona y da expresión a agregados específicos de issue publics de los que se deriva un mandato «político» 
peculiar, alternativo y competitivo respecto a la legitimación formal de los administradores públicos de origen electoral.

Desde una perspectiva análoga parece que puedan interpretarse las numerosas intervenciones de la magistratura administrativa en cualquiera de los doce estadios. También en este caso las decisiones de los jueces han tenido un notable impacto en la formulación de los procesos decisionales.

Tribunales y Consejo de Estado han sido activados, sea por iniciativa de empresas, en varios modos excluidas de las licitaciones de las obras, sea por ciudadanos y movimientos preocupados por las consecuencias ambientales de las intervenciones proyectadas. En ambas hipótesis se intenta forzar los límites angostos de los networks decisionales. En el primer caso, para romper o volver a definir ciertas disposiciones de mercado preestablecidas. En el segundo, para obtener el legítimo reconocimiento de específicas policy preferences colectivas que hayan sido negadas en sede "política». Por tanto, son intereses de género bien distinto los unos de los otros, pero vinculados por el rechazo de un exit del proceso decisional que les ha sido impuesto en vía prejudicial (o así lo perciben), aunque sea en nombre de las «razones superiores» del Mundial, de sus tiempos, de sus compromisos.

Sobre el rol de la magistratura administrativa, sobre las modalidades con que los jueces lo han interpretado y las distintas «utilizaciones» que este rol ha tenido por los demás actores en juego habría muchas observaciones que hacer. Empezando por las distintas actitudes de los Tribunales y del Consejo de Estado en el contencioso alimentado por las empresas y en el promovido por las instancias cultural-ecologistas.

Haría falta también detenerse sobre la diferente «sensibilidad» que tienen Consejo de Estado y Tribunales administrativos hacia las razones del Mundial y la «ineludible» oportunidad de las obras correspondientes. En tal sentido, es ejemplar la sentencia del Consejo de Estado del 26 de febrero de 1988 que admite el recurso del CONI contra la Sentencia del Tribunal del Lazio que había impuesto la suspensión de las obras de cubierta del Olímpico, según petición de las asociaciones ecologistas, y la admisión del recurso del CONI se basa, precisamente, en el presupuesto de que ulteriores retrasos en la continuación de las obras diferentes de la obra disputada podrían perjudicar la realización de la completa reestructuración de la instalación en su conjunto, a la espera del juicio del Tribunal. Valdría la pena, además, destacar los «estilos» de la intervención de los magistrados y de su «interacción» con los actores político-administrativos. Habría que preguntarse, por ejemplo, si en la actitud de unos y otros sean reconocibles respectivas y recíprocas propensiones al problem solving o, más bien, a la contratación o a la contraposición. Un indicio de esta oportunidad de reconocimien- 
to lo proporciona también el caso de Roma. Aquí el CONI -en buena compañía de varios administradores locales, unos cuantos «políticos de la capital» y algunos periodistas más o menos deportivos- no vaciló en tachar al Tribunal del Lazio de «irresposabilidad» pública y de connivencia con «instrumentales» denuncias ecologistas.

Pero este género de exámenes no atañe a nuestro contexto, y considerar su oportunidad quiere sólo confirmar la múltiple significación heurística del asunto de los estadios del Mundial.

\subsection{Los partidos}

Aceptando todo lo dicho sobre el fuerte carácter «personal» del rol de los administradores locales, no dejaremos de formular un cuadro de conjunto sobre las «líneas» y las posturas de los principales partidos políticos en juego, aunque sólo sea por una exigencia de plenitud descriptiva, acaso más ritual que útil en nuestro caso, pero legítima.

El período que nos interesa empieza - con alguna excepción - en las elecciones administrativas de 1985. Estas elecciones sancionaron, como es notorio, el fin de las experiencias de los gobiernos locales de izquierdas en las mayores ciudades italianas y la extensión periférica de la fórmula del «pentapartido». De nuestras doce ciudades, en el cuatrienio crucial (para nuestros fines) 1986-1989, seis tienen juntas de pentapartido, sin solución de continuidad, mientras otras cuatro atraviesan períodos de duración variable. Durante más del 70 por 100 del período considerado, en el conjunto de las doce ciudades, las alianzas de cinco partidos permanecen en el gobierno, mientras las juntas de izquierdas («monocolor» PCI o conjuntas PCI, PSI, partidos laicos) sólo cubren el 21 por 100. La absoluta preponderancia de los gobiernos de pentapartido entre las doce Administraciones cívicas interesadas es, por tanto, un primer dato de fondo.

Un segundo elemento de conjunto lo dan las dinámicas de coalición.

Cinco ciudades (Génova, Verona, Udine, Bari, Cagliari) tienen un gobierno único (de pentapartido) en todo el período. En las otras siete ciudades se registran fases más o menos largas de notable convulsión. En Roma, Nápoles y Turín la coalición de pentapartido no ha tenido alternativas. Pero los conflictos internos muchas veces han bloqueado su acción. Roma, en los mismos cuatro años, tiene cinco crisis, tres alcaldes y diez meses de «comisaría de prefectura». En Turín dos alcaldes dimiten seis veces. También en Milán y Bolonia se registran cambios de alianzas. El caso de Palermo presenta, además, una situación de «arritmia» permanente. Mientras, siguen más latentes, pero constantes, las tensiones entre los aliados en las juntas de Bolonia y Flo- 
rencia. Este cuadro de persistente inestabilidad o - según los casosde tensión normal en las relaciones políticas internas entre las coaliciones de gobierno local, por lo menos en las ciudades de nuestro «modelo» con más de 400.000 habitantes, es precisamente el segundo elemento de fondo lo que hay que tener en cuenta.

Este doble escenario - preeminencia aplastante de las juntas de pentapartido y fuerte y difusa situación de conflicto interno en las coaliciones, excepto en las ciudades de menores dimensiones- por un lado motiva que los administradores tomen responsabilidades más directas en el asunto de los estadios, bajo la dependencia de su partido: siete socialistas, seis demócrata-cristianos, dos comunistas (en el marco de doce gobiernos locales que presidían cinco alcaldes socialistas, cinco demócrata-cristianos, un comunista y un republicano). Por otro lado, ello remarca, y en parte explica, la forma fuertemente personal de la acción de los protagonistas públicos de cada caso, cuyos procesos, para avanzar, han necesitado de la propaganda (y del protagonismo) de algunos bien identificados administradores, más que de la existencia de determinadas mayorías políticas.

Hay un tercer elemento de fondo que ya he recordado y que ahora hay que comentar.

Si nos preguntáramos si los partidos, como actores colectivos locales, tienen o no su propio lugar específico entre los protagonistas de los procesos decisionales de las doce ciudades, la respuesta sería, mirándolo en su conjunto, en todas partes negativa; por lo menos, si se continúa reduciendo el caso italiano a una acepción de party government concebida como simple sinónimo de «partidocracia» (14), que es una operación frecuente en el desconocimiento periodístico y no rara en la misma reflexión de la ciencia y de la sociología política (15). Pero en la real complejidad de los procesos de policy making no encuentra un efectivo y generalizable apoyo empírico la tesis según la cual los administradores locales están realmente «incorporados» a los partidos (16) y puntualmente coordinados por actores o estructuras de par-

(14) Con un deslizamiento analítico y conceptual que acumula tal vez la desinformación periodística y la reflexión académica más notable. Para un reexamen teórico y metodológico del tema, M. Calise, Governo di partilo. Antecedenti e conseguenze in America, Bolonia, Il Mulino, 1989, en particular el capítulo introductorio.

(15) Es emblemática la introducción de Lucioano CAVALLI en la investigación de G. BET. TIn, A. Magnier y M. Talluri, 1 l Consigliere Comunale, Padova, Cedam, 1989, donde se sostiene que gracias a la centralidad del partido «... la clase dirigente municipal y la nacional resultan mucho más homogéneas y coordinadas que en otros países, y tienden a integrarse en un uso orgánico del poder», que es lo que precisamente la misma e interesante investigación de BETTIN y compañía no demuestra ni sostiene. Tanto más que esa misma investigación no pretende afrontar ni los datos ni los temas concernientes con esa pretendida coordinación, que sólo estudios de policy analysis podrían poner de relieve.

(16) Uso la expresión en una acepción conceptualmente próxima a la de A. PIZzorNo, «Il sistema pluralistico di rappresentanza», en S. BERGER (ed.), L'organizzazione degli interessi 
tido. Aún menos cuando las policies de las que se trata atañen al orden y desarrollo urbanístico de una ciudad, que precisamente son las cuestiones centrales del «gobierno local» (17).

Pero el rol de los partidos locales hay que observarlo también bajo una perspectiva distinta, más directa, pero más relevante en este contexto. Es decir, se trata de ver si influyen en la conducta de los administradores las lógicas «partisanas» internas de dichos partidos (por tanto, los arreglos y los equilibrios de poder entre corrientes, facciones, fracciones y élites respectivas) y cómo cada componente interno de los partidos utiliza los recursos políticos, legales, económicos y de know how con que pueda contar a través de hombres «propios» en el sistema político-administrativo. Y se trata de observar también si los compromisos y las lógicas de comportamiento, procedentes de pactos de coalición entre los partidos, afectan a las razones de cada administrador en los procesos de policy y vinculan la acción de sus propuestas y de su gestión, o si, en cambio, los mismos administradores no utilizan precisamente los vínculos de coalición como un específico recurso contractual para predefinir los márgenes de mediación política en la decisión que hay que tomar.

Teniendo presente, por tanto, también estas formas de interpretación, seguimos con una rápida reseña de las experiencias alcanzadas.

El ser miembro del partido por parte de los administradores que han tomado las mayores responsabilidades políticas en los procesos de los estadios evidencia - además de una subrepresentación de los partidos laicos menores, aún presentes en casi todas las juntas interesadas - una clara y condicionante presencia socialista.

En el tema de los estadios, los militantes del PSI obtienen un «rendimiento» aún superior al ya óptimo en términos de cargos de alcalde (18). Hasta tal punto que, en una perspectiva analítica que conjugase los varios niveles de gobierno en juego, la operación del Mundial quedaría marcada por la relevante connotación del Partido Socialista Italiano.

Socialistas son, en efecto, los administradores más comprometidos en el asunto de los estadios en Turín, Génova, Bari y Cagliari. Pero también en Milán, Verona y Bolonia tienen administradores socialistas en primer plano. No es necesario recordar que todo el asunto del Mundial ha sido promovido por el aval decisivo de un presidente de Gobierno socialista, el cual se adhiere a la idea de un presidente de la FIGC del área socialista, quien, a su vez, sucediendo a otros dos mi-

nell'Europa Occidentale, Il Mulino, Bolonia, 1983, p. 371, donde se define el grado de autonomía o de heteronomía de una organización con respecto del Estado.

(17) Sobre el tema ver la introducción de Bruno DENTE en L. BOBBio et al., Metropoli per progetti, op. cit.

(18) Véase BETtin y MAGNieR, op. cit., p. 167. 
nistros socialistas, aseguraría al PSI la gestión del Ministerio de Turismo y Espectáculos para la preparación y celebración del gran evento.

De ahí a la hipótesis de una fundamental calificación de partido - precisamente del partido «craxiano»- a toda la estrategia del Mundial falta poco, aunque la relevancia estratégica del acontecimiento supone un horizonte explicativo mucho más amplio. Seguramente, el rol de este partido y su propensión a representarlo reflejan el síntoma de una sensibilidad destacada de los socialistas italianos hacia las cuestiones y las perspectivas de la renovación urbana y metropolitana por medio de las políticas de los grandes proyectos de urgencia garantizada y por medio de las sinergias de los grandes grupos financieros privados y públicos. Y, por el contrario, delatan el escaso crédito que en el PSI se atribuye a los modelos «sinópticos» de la tradición urbanística y la intolerancia socialista para las «trabas» políticas y de desarrollo de los «planes». Mientras, en el caso en cuestión, el evento futbolístico y la esperanza de benéficas y múltiples consecuencias de innovación urbana y metropolitana ofrecían una óptima oportunidad a estas posiciones, apartándolas de un explícito diseño de «gran reforma» de la instrumentación urbanística y del gobierno local.

Se interprete como se interprete, la visibilidad peculiar de los administradores socialistas en los procesos decisionales locales es un dato comprobado. Es difícil percibir en esto el paso de las contingentes circunstancias municipales que puedan alimentar esta situación privilegiada, de la fuerte implicación del PSI en todo el asunto a nivel nacional y de la capacidad de la dirección general del partido para orientar gobiernos, coaliciones y distribuciones de los cargos de concejal con una cuidadosa dirección.

Es verdad que los encargos municipales, que se revelan decisivos en la dirección de los procesos decisionales de los doce municipios interesados, son de lo más vario: siete concejales para el deporte, dos concejales para las construcciones públicas, un concejal para la hacienda pública, un concejal para las obras públicas. Así como es verdad que, en ciertas circunstancias, disponer del cargo de alcalde cuenta, pero en la mayoría de los casos no parece ser el factor resolutivo. Los miembros de las juntas que se empeñan más directamente en el decision making de los estadios lo hacen por los títulos más varios de concejal; por lo cual, el pertenecer al partido, en nuestro caso, parece que corresponda precisamente a un diseño unitario y centralizado.

Pero aun si así fuera, tal conexión no querría decir — por sí misma- que el partido de que se trata ha demostrado ser capaz de coordinar, desde el centro, la conducta de sus administradores locales. Más verosímil acaso es que el simple pertenecer al partido, por parte de unos administradores locales y del directorio político de la operación entera (Ministerio de Turismo y CONI), haya podido hacer más flui- 
dos y eficaces los accesos a las autoridades nacionales de unas Administraciones locales. Y considerada la importancia que en la coyuntura tendrían las negociaciones directas entre las doce ciudades y las Administraciones competentes, es plausible que una «regulación» semejante de los encargos municipales y de las conexiones entre «centro» $\mathrm{y}$ «periferia» del sistema político-administrativo haya sido, por lo menos, querida en el partido «craxiano».

En el caso del PCI, en juego está el partido de los concejales, de los grupos municipales de los asesores, no el PCI, máquina local de partido y organización de movilización colectiva.

No sabemos si en las elecciones o en las Case del Popolo se hablaba del Mundial y si se discutía de los estadios como cuestiones de política y de Administración local. En todo caso, los ecos de un eventual debate político no se han oído en las aulas municipales, ni en las páginas locales de l'Unitá, acaso sólo en la fase más próxima a la celebración del evento.

Cuando en las obras de los estadios y en las de las construcciones accesorias se produjeron veinticuatro muertes y casi 700 heridos, el partido se asoció, por supuesto, a la protesta sindical. Criticó y lamentó los trabajos apresurados y el menosprecio por normas elementales de seguridad (y no sólo por aquellos «planes» de seguridad que las empresas adjudicatarias debían haber tomado según la Ley 205, de 1989), la falta de control de las empresas y microempresas subarrendadoras. Y apoyó al juez Ayala, quien en Palermo cierra y secuestra la obra de La Favorita por el derrumbe de dos pilares de acero que atropellan y matan a cuatro obreros y hieren a dos. Pero la protesta comunista no tiene nada de «ideológico». No ataca - ni con la invectiva ni con la sátira - al unanimismo un poco zafio que sopla sobre el gran evento.

Frente a la torpe evocación de la fatalidad y del sino cruel que, con los primeros accidentes en las obras, se repite en los «análisis» hechos por algunos de los promotores nacionales del caso, la respuesta del PCI no es la indignación moral, la movilización cultural, la oposición social. Y la misma fórmula de los «homicidios blancos», para aludir a los accidentes mortales dentro y alrededor de las obras de los estadios, el PCI la deja bien guardada bajo naftalina. También la crítica parlamentaria sobre las simplificaciones de procedimientos, que el Decreto sobre los estadios introduce para la asignación de los trabajos, está enfocada toda en rigurosa clave de legalidad «metodológica», no tiene nada de culturalmente contrario ni, menos aún, de «prejuicio» sobre el mérito.

La impresión, en conjunto, es que el partido haya optado por una aceptación resignada - aun "crítica» y «vigilante»- del ineludible evento. Con una actitud en que sopla el bien arraigado terror de su «diferencia», particularmente sobre una operación de tan amplia su- 
gestión «nacional-popular» (capaz - tal vez- de avivar antiguos anatemas contra los partidos «antisistema» para el que se atreviese a no conformarse). Por otra parte, no se ve por qué, en el ex «pueblo comunista», en su membership y en sus élites centrales y periféricas (19), el fútbol debería ser un catalizador menos fuerte y menos ratificatorio que en el conjunto de la sociedad italiana y de sus referentes políticos colectivos. La sensación es, en las ciudades en que el partido tiene responsabilidades administrativas más fuertes, que el Mundial se mire con ese desencantado pesimismo de la razón, caso un poco cínico que junta al concejal comunista con el socialista, el demócristiano... con el de cualquier otro partido, en el confiar al evento funciones múltiples o expectativas de «desbloqueo» de toda una serie de issues siempre aplazadas (20).

Por todo ello, cuando está en la oposición, el PCI prefiere debatir singularmente aspectos determinados de las opciones en discusión y, en todo caso, aprovecharse de algún escamoteo de procedimiento (por ejemplo, el abstenerse o ausentarse en el momento de un voto en aula) para «disentir», evitando una oposición de raíz o intentos de movilización contestataria de la opinión pública.

En el enfoque de la crítica comunista se hallan específicas opciones de proyectos y determinadas modalidades de realización y de financiación de las intervenciones, o bien, ciertos efectos urbanísticos o ambientales: la elección del sitio en Bari, la cubierta del Bisagno en Génova, la oposición al proyecto Fininvest y a la indeterminación de sus gastos en Milán, el rechazo de la hipótesis «romanista» para un nuevo estadio en lugar del Olímpico. Pero hay que remarcarlo siempre con la prudencia de quien no quiere arriesgar la celebración del Mundial. Aun porque, si los concejales comunistas se oponen de una forma más dura y prejudicial, cuando pasen de la oposición al gobierno de las ciudades o llegue el momento de las decisiones de puesta en obra de los proyectos que resueltamente han apoyado o rechazado, el partido acaba con enredarse en vínculos de cogestión molestos. Así fue, en la primera hipótesis, en el momento en que el PCI entra en la mayoría y en el gobierno, que la oposición al proyecto de Berlusconi se reduce a la disputa de los hipotéticos «palcos». Y es así, en la segunda, que el mismo apoyo comunista para la reestructuración del Olimpico y su oposición al nuevo estadio de Viola acabará con ser una indefinida tole-

(19) En general, sobre los orígenes ideológicos del «deporte socialista» en el movimiento obrero internacional, J. H. HoBERMAN, Politica e Sport. Il corpo nella ideologia politiche del 800 e del 900, Il Mulino, Bolonia, 1988, cap. VII.

(20) En vez de considerar a los mundiales «... una de las tres plagas que pueden golpear a las ciudades»: olimpiadas, exposiciones universales y copas del mundo de fútbol (como afirma B. Zevi, en Camera dei Deputati, Atti parlamentari, resoconto sommario, sesión del 3 de mayo de 1989 , p. 15). 
rancia comunista respecto a cada decisión y a cada nuevo gasto que supone la reconstrucción de la vieja instalación.

Por supuesto, a la prudencia fundamental del PCI hay que añadir sus difíciles armonías entre propensiones a la «lucha» y propensiones al «gobierno» de las ciudades. He aquí, pues, que en Turín el PCI comparte, con un sector de la DC, las razones «ético-sociales» y administrativas contrarias a la hipótesis de una nueva instalación, compartiendo, al mismo tiempo, el deseo de no homologarse al «poderío» de la FIAT. Pero una vez metidos en el nuevo estadio, los representantes comunistas en la comisión política que otorgará la concesión votarán por Acqua Marcia, más por un desaire al grupo de Turín que por una adhesión a la estrategia empresarial «alternativista» del PSI. Desde ese momento, el grupo del PCI estará en la oposición de manera vigilante y meticulosa, obsesionado por la subida de los costes no previstos. Acosará a la mayoría y logrará dividirla e impedir o parar, a menudo, el proceso decisional. Sin embargo, el PCI evitará siempre cualquier choque directo con el PSI, que es el patrocinador más claro de toda la operación anti-FIAT, pues es con el PSI que el PCI espera volver a gobernar la ciudad.

En fin, cuando y donde el PCI está en el gobierno de las ciudades no acentúa sólo su corte pragmático de «partido de los administradores», sino que, si sus responsabilidades gubernamentales tienen un específico arraigo «subcultural», revela también las específicas preocupaciones empresariales de su «sistema de poder». De aquí, en el caso de Bolonia, la preferencia tenaz por el Consorzio Cooperative Costruttori en defensa de una posición hegemónica suya en un mercado doméstico emblemático, que llega a ser un elemento condicionante para la misma opción de proyectos que allí se hace.

$\mathrm{El}$ caso de la DC es más sencillo, por lo menos para el lector ajeno al asunto, porque es inimaginable una real y amplia vacilación detrás del sí demócrata-cristiano al Mundial. Sólo una pequeña minoría católica hubiera podido oponer una visión cristiana del deporte contraria a su comercialización, a su idolatría televisiva hacia sus héroes, a las modernas políticas de control y contención de los impulsos sociales por medio de las magnificiencias tecnológicas del panem et circenses. $\mathrm{Al}$ cuerpo vivo y concreto de la DC no le cabría la menor duda sociológica, ni sentimientos de culpa morales o seudo-culturales.

Por otra parte, también es verdad que la DC - a nivel de su imagen nacional - no tiene la paternidad originaria de la entera oposición del Mundial, ni asume en ella una clara visibilidad política. Sin embargo, la presencia e influencia demócrata-cristiana en las cumbres gubernamentales y asociaciones del espectáculo futbolístico tiene raíces antiguas y profundas, así como las tiene en aquella descomunal policy community que son los millones de muchachos y adultos que cada do- 
mingo corren detrás de un balón con la camiseta de cualquier asociación afiliada a la Federación Italiana de Fútbol. Por tanto, sobre la oportunidad del Mundial, en la DC, nulla quaestio.

Pero el caso de la DC demuestra aún la fisiológica propensión demócrata-cristiana a adherirse a las coyunturas del gobierno local y a las lógicas territoriales que empapan la vida política de cada ciudad, así como la organización del partido (21). Y aunque nuestros doce estadios representan una casuística muy exigua, en todo caso, es notable la variedad de situaciones y actitudes inscribibles en las filas de la DC.

En las ciudades en que está en el gobierno, la DC promueve o apoya la operación de los estadios, pero con modalidades diferentes de un caso a otro. En Milán, un concejal demócrata-cristiano y militante de Comunione e liberazione logra poner en marcha, con eficacia, el proceso decisional y sintonizar con la estrategia de Berlusconi de revolución cultural y organizadora del deporte milanés, basada en un nuevo gran estadio para un público de sanos y fieles supporters que van a $S a n$ Siro con familia. También en Nápoles la DC tiene un rol crucial, sea por las soluciones adoptadas, sea por su gestión, pero es un rol jugado en la máquina de partido, en su articulación de corrientes y en el enredo de sus alianzas con los intereses empresariales que predominan en la ciudad. Es una corriente precisa la que sobresale y son sus aliados en el empresariado local y en la misma burocracia municipal los que imponen una preferencia propia de proyectos y empresas. Y se impone a otra corriente del partido que posee apoyos significativos dentro del establisbment demócrata-cristiano napolitano.

No pertenecen a esta especie los pacíficos casos de Udine y Verona. En ambas ciudades la operación de los estadios puede actuar sobre acuerdos de gran estabilidad política, basados en el rol claramente hegemónico y compacto de la DC. Los próceres DC en las Administraciones municipales están igualmente bien relacionados con el ambiente futbolístico ciudadano. A veces están juntos en los mismos órganos sociales de los dos equipos de la ciudad y tienen relaciones de firme colaboración con el empresariado de la construcción local. El cual, a su vez, está en fuerte sintonía con el mismo ambiente futbolístico (en particular en la capital milanesa). En resumen, Verona y Udine son los dos casos en que la DC puede jugar un fácil papel de coordinación de los procesos decisionales, por otra parte ya de por sí muy integrados y lineales.

Diferente, casi peculiar, es el caso de Cagliari. Aquí también la DC está en el gobierno. Es una DC de antigua tradición dorotea y de antigua fe futbolística. Su decadencia futbolística coincide con el con-

(21) Sobre esta capaciad de adhesión fisiológica de la DC, ver P. ALLuM, «Al cuore della Democrazia Cristiana: il caso veneto», en Inchiesta, 1985, núm. 70, pp. 54-63. 
cluirse de una conexión político-empresarial que había conjugado el doroteísmo cagliaritano y la petroquímica sarda en una específica «forma de gobierno» local y regional. La operación Mundial ve el ascenso a concejal para el deporte de un no demócrata-cristiano, después de un indiscutido y pluridecenal dominio DC; un nuevo y determinado empresario político de fe socialista. La DC mantiene, en todo caso, el sillón de alcalde. La DC, por tanto, soporta los vínculos de coalición del gobierno municipal y vive la cuestión de la reestructuración del estadio al margen del proceso decisional.

Existen, además, los casos en que el rol local de la DC forma parte o se cruza con «casos nacionales» del universo demócrata-cristiano. Así, en Palermo, donde no es precisamente la DC la que guía, controla y orienta la cuestión del estadio ciudadano y sus pertinencias urbanísticas, sino más bien el propio alcalde Orlando, que emplea plenamente su credibilidad de regenerador de la vida político-administrativa palermitana. $Y$ así es también en Roma, donde la DC pone de manifiesto las muchas caras de su conflicto interno y donde cada actor puede disfrutar de los recursos, impulsos y tutelas que se derivan de su intensa proximidad a las lógicas y a las dinámicas del escenario político «nacional». Pero también donde cada actor puede estar obligado a pagar los precios de la coyuntura política «romana» y de sus contingencias de coalición y/o de oposición internas y externas del partido católico.

Menos visible, pero no menos real, es el conflicto interno de la DC en el caso turinés. La Democracia Cristiana se hace responsable de todas las opciones que han llevado la Administración municipal a la solución adoptada. La misma opción por un nuevo estadio tiene el pleno aval de la DC. Pero, en general, el asentimiento y el acuerdo van juntos siempre con algún problema interno y con reiteradas protestas hacia el concejal demócrata-cristiano que «flanquea» el rol central del concejal socialista para el deporte.

Una situación análoga se puede hallar en Génova, donde la DC ocupa un rol relevante para las obras complementarias, no para el estadio, $y$ en forma consensual deja libertad al PSI.

Bari cierra el grupo de ciudades en que la DC tiene responsabilidades de gobierno. Aquí es realmente difícil evaluar el rol del partido local. Es demasiado apremiante el peso político y empresarial del presidente de la FIGC en el escenario político y económico de la ciudad como para imaginar una $\mathrm{DC}$ que se sitúe al margen. En efecto, los problemas con que la DC de Bari se enfrenta no atañen al nuevo estadio, sino a los intereses del abigarrado empresario de obras públicas local y a su confrontación con los grandes operadores del mercado.

Las dos ciudades en que la DC no está en el gobierno son Bolonia y Florencia. En la primera, la DC lleva su oposición sobre dos vertien- 
tes. En primer lugar, ofrece un vano apoyo a las hipótesis partidarias de un nuevo estadio, según las dos propuestas privadas en competencia, proporcionando su ayuda a la débil solicitud del Bolonia F. C. y a la más enérgica del CONI provincial. En segundo lugar, protesta contra la presunta voluntad (PCI, PSI, PRI) de favorecer, en cualquier modo, al Consorzio Cooperative Construttori, en detrimento del empresariado privado y local en particular.

En Florencia la oposición demócrata-cristiana es decididamente prudente; sólo un par de concejales de la DC en Palazzo Vecchio hablan sobre las cuestiones del estadio Comunal y del otro para la gimnasia atlética. Firman - casi siempre juntos- una serie de críticas oficiales, pero siempre con tonos moderados y enfocando opciones técnicas marginales más que aspectos decisivos. En particular, objeto de sus críticas son el estadio de gimnasia, que debería sustituir la pista derribada en la reestructuración de la vieja instalación, el tiempo de realización del mismo, y su falta de relación con las obras del Comunal. Por otra parte, tal cautela se puede explicar durante el período de la junta de pentapartido hasta las elecciones de 1985; precisamente la DC, con su concejal para el deporte, había aprobado el planteamiento de las obras para el estadio de Pier Luigi Nervi, empleando para la operación una cuota relevante de su crédito político.

\section{LOS «ARQUITECTOS»}

He procurado determinar cuál ha sido el rol de los proyectistas sobre la base de un prejuicio previo. En este género de políticas públicas, los expertos, los técnicos, los proyectistas..., en suma, los profesionales del asesoramiento urbanístico y del planteamiento de construcciones (sean ellos procedentes de una expertise principalmente arquitectónica, o también ecológica, jurídica o económica), acaban con tener un rol propio de policy makers. No se trata tan sólo del asesor fuerte y creíble por su autoridad académica y/o profesional y por el crédito político-cultural - sino también político de partido- que se da en ciertas coaliciones de gobierno local, ni es sólo el técnico que elabora y sugiere aquellas soluciones y alternativas planificadoras y de planteamientos aptas para hacer realizables las opciones políticas adoptadas en la empresa privada o en la Administración pública, sino que también es el asesor quien elabora y promueve aquellas mismas preferencias políticas o se hace garante y partidario de ellas con cualquier actor en juego. Es él quien verifica o traza las vías y modalidades de la mediación política entre los demás participantes con el fin de defender la integridad y el buen fin de su «justa causa»: el proyecto o el plan que lleva su firma. Es, por tanto, un asesor que aconseja a los va- 
rios «príncipes» en campo, sin desdeñar la contienda política ni el humo de los despachos de la negociación política. En suma, es un asesor policy maker dispuesto a asumir, sobre varias mesas y al mismo tiempo, el papel, sea del policy entrepreneur como el del policy activist.

Precisamente la debilidad burocrática y la incertidumbre cognoscitiva y estratégica de los actores político-administrativos alimentan este rol tan condicionante del asesoramiento y del planteamiento privado y la expansión dominante de sus funciones y de su misma presencia. El asunto debería resultar tanto más plausible cuanto, como en el caso de los estadios, las decisiones en manos de las Administraciones locales suscitan expectativas públicas de obras con peculiar valor arquitectónico, estético, monumental.

El punto de partida sobre el que he vuelto a leer los varios procesos decisionales se ha demostrado fundado. Pero con algún correctivo. Efectivamente, se han verificado situaciones en las que los proyectistas han actuado como actores intrinsecos en el proceso decisional. O sea, han participado directa y activamente en la definición del problema o en su formulación originaria. Así ha ocurrido en Génova, Milán, Bari y Florencia. Mutatis mutandis en las tres ciudades, el «arquitecto» ha contribuido a limpiar preliminarmente el campo de las posibles alternativas estratégicas y ha facilitado la estructuración del network decisional en sus actores esenciales. «De alli», de los resultados de su opción de los proyectos, el proceso se iría desarrollando.

Sin embargo, el empuje del planteamiento se ha revelado realmente resolutivo sí y en cuanto se haya relacionado con los intentos estratégicos del actor que ha pensado dar arranque al proceso por medio de una definición o redefinición «propia» del problema. Es decir, el proyecto técnico logra vincular el proceso decisional en sus posibles soluciones y, por tanto, el número de sus participantes, si forma parte de la hipótesis estratégica de quien piensa iniciar y conducir el decision making, estableciendo sus presupuestos sustantivos. En suma, si el proyecto y el proyectista son un «recurso» para el decisor estratégico.

En Milán el proyecto Ragazzini y Hoffer (formulado desde la égida berlusconiana) es plenamente funcional a la hipótesis del megaestudio a «regalar» a la ciudad para celebrar y sancionar su animus más vano, vital y dinámico, y su nuevo y moderno héroe. Quien, como actor del proceso decisional, «confeccionará» su homenaje a la ciudad con la inusual elegancia de un formal retiro del escenario político y de la competición entre las empresas, en cuanto habrá hecho irrefutable su opción. En Génova el proyecto Gregotti actúa de gran y simbólica manifestación de la específica capacidad de empresa genovesa (en los umbrales de una nueva calificación económica de la ciudad), según una hipótesis reciamente alimentada por un bien determinado policy activist (el presidente de la delegación regional del CONI) que se entre- 
gará a tiempo pleno al apoyo y «tutela» del proceso, superando la inercia inicial político-administrativa hacia el Mundial. En Bari, Renzo Piano, con una impresionante rapidez de propuestas, formula un proyecto arquitectónico renovador que tiene éxito precisamente en cuanto puede hacer indiscutible la «justa preferencia» del nuevo estadio deseado y construido por el grupo Matarrese y por los operadores que él añade. Sólo en Florencia el rol del planteamiento parece prescindir de hipótesis estratégicas de contexto o prejudiciales de otros policy makers. Los administradores locales, depositarios de la cuestión del estadio, no tieneri mandatos explícitos o definidos en que apoyarse por lo que se refiere a las soluciones adoptables. Es el estudio Gamberini el que formula las posibles alternativas para el decisor público. Y cualquiera que sea la opción de la Administración, es el proyectista quien mantiene una especie de originaria paternidad "política» de la solución adoptada y actúa realmente como su padre natural. Debe defender en la operación un sustancial empleo de imagen y autoridad técnica y profesional y su capacidad de proyectista debe mediarla con una construcción ya prestigiosa, dotada de su firme relevancia histórico-artística. Así, el arquitecto se expone en persona, promueve, estimula, propone, media, solicita y garantiza a los actores político-administrativos acerca de sus incertidumbres y los riesgos de sus opciones. En suma, el proyectista llega a ser el fiador técnico del policy making, pero es también un policy maker de primer plano. Es él quien proporciona la originaria formulación técnica del problema que hay que resolver, sobre el que se apoyará el proceso decisional entero. Es suyo el proyecto que se pone como previa y legítima alternativa a la hipótesis -aún defendible y susceptible de grandes asentimientos- de un estadio nuevo para el fútbol. Y es suyo el proyecto sobre el cual $a b$ initio se construye aquella segura sintonía de intentos entre los dos administradores (uno demócrata-cristiano y el otro comunista) que se sucederán en la guía del sector competente de la Administración municipal y que defenderán la cuestión del estadio de los posibles choques del cambio de coaliciones efectuado en el Ayuntamiento después de las elecciones administrativas del 85 .

En todo caso, prescindiendo de la peculiaridad del caso florentino, esta directa eficiencia del planteamiento hacia las exigencias de quien piensa asumir la dirección del proceso, o al menos un discreto, pero sustancial control del mismo, no es una deminutio capitis del proyectista hacia el actor (sea policy activist o maker), su solicitante o usuario. Precisamente ello implica una mayor autonomía y visibilidad de sus planteamientos. Los cuales, en efecto, resultan tutelados por una directa y difundida forma de responsabilidad profesional del proyectista frente a los problemas que el mismo proyecto pueda levantar en el ámbito de la realización y que, si se da el caso, el propio «cliente» está dispuesto a reconocer. 
En las demás ciudades, hasta aquí no mencionadas, el proyectista asume un papel que, si no menos importante, es por cierto menos visible. Seguramente más «aplastado» o más integrado en la acción de las empresas hacia las Administraciones, o bien en la conducta de las Administraciones hacia las empresas.

A la primera especie de estrecha conexión pertenece el caso de Turín, donde la empresa concesionaria y sus numerosos subarrendatarios trabajarán sobre un proyecto del arquitecto Hutter elaborado por cuenta de un competidor derrotado $\mathrm{y}$, además, con una diferente colocación urbanística de la instalación.

En cambio, todos los demás estadios configuran una estrecha integración del planteamiento en la iniciativa político-administrativa. En ciertos casos esta integración resulta «afianzada» porque el proyectista pertenece al mercado local de las obras públicas (Bolonia, Udine, Verona, donde constructor y proyectista son los mismos que han edificado la instalación originaria), o bien por su específica práctica profesional de construcciones y establecimientos deportivos y con los relativos entes promotores y proveedores (es lo que acaece en Cagliari, Nápoles y Roma).

\section{LAS EMPRESAS CONSTRUCTORAS}

El tema de los estadios y del Mundial coincide con un período de intensa reorganización del mercado de las obras públicas. Los operadores aguantan un difícil proceso de reestructuración del sector y de una nueva dimensión empresarial contra la extrema fragmentación que siempre ha caracterizado al empresario italiano de este sector, y su consolidación alrededor de grandes grupos privados y públicos.

La actitud de las empresas constructoras en la cuestión de los estadios refleja este esfuerzo general (que se ha reflejado en las modalidades mismas de adjudicación de las obras).

Por un lado, los operadores más importantes aprovechan la oportunidad y el particular valor de promoción de los estadios y del Mundial para experimentar o consolidar alianzas y sinergias de empresa en consideración de aquella «revolución urbana», según la cual la ciudad, en su dimensión metropolitana, debería «... acoger e impulsar las principales características estructurales» del desarrollo económico y social y que hacen imaginar a Italia como una inminente, inmensa obra y un gran mercado europeo con pocos «planos» y muchos «proyectos». Por otro lado, están en juego las empresas menores con posiciones de mercado obviamente más débiles con respecto a las empresas mayores, pero con raíces locales (o localistas) aún bastante tenaces para imponer una presencia propia y una tutela política propia aún en las situa- 
ciones de oligopolio aparentemente mejor estructuradas, o al menos, para proponerse como un «problema» no fácilmente eludible ni para los administradores locales ni para las empresas económicamente más fuertes.

Nuestros doce estadios indican - por su parte- que se trata de un esfuerzo nada concluido y con resultados todavía dudosos. Las estrategias de largo alcance y la reactividad coyuntural de la gran empresa se confrontan y se cruzan con los buenos oficios de las empresas pequeñas y medianas en los entresijos del Gobierno y Administración locales, así como con el legislador estatal. Mientras, se superponen y cruzan las coaliciones y los oligopolios político-empresariales que se desarrollan entre «centro» y "periferia» del sistema político-administrativo. Además, ya que en nuestro caso están en discusión obras que pertenecen al espectáculo futbolístico, entra en juego un recurso empresarial específico y discriminatorio que unas empresas tienen por su cuenta y que otras tan sólo pueden tratar de adquirir o subrogar: la contigüidad con el ambiente del fútbol y el mundo de sus negocios.

Ahora bien, si considerásemos la experiencia de los estadios como un indicio de alcance general, los resultados de nuestra investigación sobre este tipo de actores nos llevarían a la conclusión de que un «mercado» real de las obras públicas, en licitaciones libres entre grandes y modernas empresas del sector y con reglas precisas de competición, sigue siendo un lejano espejismo. Obviamente, sería una generalización excesiva dada la exigüidad de nuestro observatorio. Sin embargo, claro está que la ocasión de los estadios para el Mundial no ha sido interpretada para nada bajo una perspectiva de racionalización estructural del mercado y también es evidente que justamente los más directamente interesados no se han movido en tal dirección.

En las doce ciudades del Mundial los «constructores» enfatizan su real y habitual función de policy makers. Casi en cualquier parte su primer paso es el intento de orientar, desde el inicio, la definición del problema por parte de las Administraciones locales o, al menos, de favorecer sucesivamente su redefinición. Por este motivo se sirven de sus recursos económicos, de know bow, de frecuentación de las arenas político-administrativas locales o también gubernamentales $\mathrm{y} / \mathrm{o}$ parlamentarias. Otro paso consiste en «organizar» preventivamente el mercado para reducir, en lo posible, los imprevistos de los procedimientos de adjudicación (y, si se da el caso, para concordar una leadership propia entre las empresas en competición). De aquí la promoción de las oportunas coaliciones entre las empresas virtualmente en competición. $Y$ de aquí el correlativo intento de saturar la oferta potencial del mercado por medio de grupos compuestos entre empresas de diferente especialización productiva y comercial. Un tercer paso es el perfeccionamiento del primero: agregar o recuperar el empresariado menor y/o 
local del sector, eventualmente excluido de la primera repartición de los trabajos.

Por supuesto, la sucesión de los tres movimientos puede ser diferente y ciertos pasajes pueden resultar sólo esbozados. Pero hallamos huellas o trazas de estos pasos en todas las experiencias consideradas, con la excepción - acaso- de los dos casos de menor complejidad de proceso (Udine y Verona), donde, en todo caso, el empresario está muy metido en el establisbment político y empresarial del lugar y donde, aún menos, es lícito hablar de selección de mercado. En cambio, en las demás ciudades los signos de estos pasos son bien visibles.

Lo son en Roma, donde el intento de definir previamente la cuestión por decidir está muy fundamentado y dispone del empeño directo del presidente de la sociedad del Roma, F. C., que apoya a la empresa interesada con toda su currency política de partido. También son visibles en Bolonia, donde el intento de definir (mejor dicho, de redefinir) el problema es perseguido, aquí también con amplios apoyos políticos, por dos grupos privados (Ligresti y Marchesini separadamente y en momentos distintos) que tratan de forzar la inicial ventaja de las cooperativas. Y lo mismo sucede también en Turín, donde el «mercado» no está organizado, sino abiertamente sustituido por una específica «arena» política —externa a la Administración propiamente dicha- a la que se le confía expresamente la elección de quién ira a realizar y dirigir la nueva instalación. Y cuando Acqua Marcia gana este abierto reto político contra la FIAT y en su misma casa, en seguida va a procurar subarrendar los trabajos a un montón de empresas, la mayoría del área turinesa.

$\mathrm{El}$ «respeto» hacia el empresario local es precisamente una constante y juega en una doble modalidad. La primera es la marcada propensión a repartir las obras de los estadios entre empresas locales menores por medio de empresas de mayores dimensiones, en cuanto éstas hayan adquirido la concesión de la obra. Así ha sucedido en Cagliari, Palermo, Florencia y Bari. Mientras en Bolonia precisamente la falta de respeto por tales «reglas» por parte del consorcio de cooperativas, ganador de la concesión, ha alimentado la única verdadera razón de conflicto político que ha acompañado la reestructuración del Dall'Ara, la segunda modalidad consiste en la atención que también los grandes grupos parecen reservar a las raíces territoriales de su concurrentes de análoga importancia, promoviendo o aceptando las oportunas soluciones del consorcio (es el caso, por ejemplo, de Génova).

En el conjunto de los casos examinados, lo mucho de regulación política y lo poco de mercado que parecen caracterizar la acción de las empresas interesadas en los estadios, en todo caso, no debe sorprender. Han sido precisamente los actores políticos que en sede gubernamental y parlamentaria han dado a toda la operación los necesa- 
rios apoyos financieros y normativos que han querido evitar cuidadosamente que el Mundial fuese una ocasión para renovar las lógicas político-administrativas y empresariales que presiden las obras públicas. De aquí el planteamiento preferentemente de iniciativa «privada» y de «negocio» de las posibles modalidades de otorgamiento de los trabajos, según las disposiciones del Decreto-ley sobre los estadios (Decreto-ley 2/1987), así como de la Ley de Conversión (núm. 65, de 1987).

Son opciones que entienden estimular un artificial ingenio para sostener simbólicamente una importante policy urbanística y de infraestructura y legitimar un específico instrumento decisional y financiero para que sea realizable. En ello, la derogación de la «norma» se afirma e institucionaliza como regulación privada y el mercado es sustituido por la mediación y la repartición político-administrativa.

\section{LOS EQUIPOS DE FUTBOL DE LAS DOCE CIUDADES}

Se podía esperar acaso un rol mayor de las sociedades futbolísticas que disfrutan de forma institucional de los estadios. En realidad, los clubes de las ciudades interesadas protestan, sobre todo, cuando - $y$ donde- los equipos padecen las molestias y los daños de las obras de reestructuración en curso. $\mathrm{Y}$ si a las incomodidades se agregan el forzoso paro de las instalaciones $y$, acaso también, los resultados negativos de los partidos y de los ingresos. No es que este género de quejas no ha pesado sobre los relativos asuntos político-administrativos, pero donde se ha oído el lamento de los equipos ha influido más en el contexto que en el mérito de los procesos de policy en marcha. La marginación de los clubes de fútbol no era previsible. La reestructuración de los estadios no hace más que valorizar el espectáculo futbolístico del campeonato italiano, sobre todo en la perspectiva de un buen resultado del equipo nacional, con previsibles impactos económicos para las mismas sociedades, y esto aunque las nuevas y más confortables instalaciones sólo llamasen al estadio al público de los ultras y no lograsen incentivar las campañas de los abonos de los clubes. En todo caso, en efecto, serían siempre las sociedades futbolísticas las que producen el más grande entertainment de masa italiano, y siempre a su cargo estaría la producción del gran producto televisivo que de él procede, en sus ingredientes principales (las hazañas de los futbolistas en los campos de juego y las de los aficionados en las graderías y alrededor de los estadios). Por tanto, la preparación de «Italia 90» podía haberse interpretado por parte de las sociedades como la chance para una responsabilización de empresa más conforme a la importancia económica y social del fútbol profesional y a su cambio multimedia, como precisamente el Mundial iba a sancionar y celebrar. En suma, hubiese sido 
más que plausible una implicación más activa, en un plan de propuestas, proyectos y gestiones de las sociedades con respecto a las nuevas instalaciones, o sea, a los medios esenciales de su actividad productiva.

Pero no ha sido así. Y las mismas excepciones del asunto ahora formulado lo demuestran.

En Milán es Berlusconi quien se mueve, pero la Inter se queda mirando. En Turín hay un intento de la Juventus para promover un nuevo estadio para el espectáculo fútbolístico solamente, pero la FIAT no lo apoya. La FIAT misma se va a empeñar en ello sólo cuando piensa contrastar al «Acqua Marcia» en una operación que no tiene detrás una estrategia y originaria opción de empresariado futbolístico. También el presidente de la Roma, Viola, enfoca su propuesta en un diseño urbanístico que atañe a la Administración de la capital, sus estrategias y las de los operadores económicos en que se apoya, más que a los destinos específicos de una empresa que produce fútbol-espectáculo. Lo mismo podría decirse de Nápoles y del intento de Ferlaino. Pero aún más emblemático podría aparecer el desinterés de los Pontello por el estadio de la Fiorentina y su intento, en cambio, de adjudicarse las obras de San Siro.

Probablemente, sin mirar atrás, hay que reafirmar solamente que el football profesional y televisivo, a pesar de las dimensiones y efectos del business que representa y que alimenta, aún no ha sabido expresar una clase empresarial peculiar suya que lo franquee de las infinitas funcionalidades y rentabilidades externas que han acompañado la tradición cultural y económica del fútbol en este país. Las señales de nuevas y específicas formas empresariales, en algún caso son conspicuas (y muy enfatizadas), pero aún sólo señales. Por otra parte, ir por este rumbo significa también mudar y «aclarar» los términos de aquella simbiosis «sistémica» entre espectáculo futbolístico y clase política y empresarial de donde he empezado estas consideraciones. Esto representa, más que una perspectiva concreta, una baza todavía por jugar.

Es también por este motivo que no resulta palpable aquella especie de conglomerado futbolístico/político/industrial que, por lo menos, como observador externo, había esperado descubrir y que el fútbol profesional, en cuanto tal, podría dejar entrever como estructura propia, pero que los ejemplos ahora citados proponen como hipótesis interpretativa aún por demostrar.

\section{LOS INTERESES «AJENOS»}

Hablo de intereses ajenos para distinguirlos de aquellos que han tenido una relación «intrínseca» con los procesos decisionales de los estadios, sin querer rebajar el peso de su influencia sobre los resultados 
de los procesos, pues en algunos casos ha sido hasta remarcable, aunque nunca clara o directamente decisiva.

Ya dije que debo dejar para otra ocasión una relación específica de ello, que deberá concernir, en primer lugar, a los sindicatos. Las grandes organizaciones sindicales y los mismos sindicatos de las categorías más comprometidas, esencialmente parece que se alinean bajo las banderas de la extraordinaria necesidad y urgencia del campeonato del mundo. Es una alineación que lleva detrás una sustancial adhesión a la iniciativa en general, un contagioso amor por el fútbol (22) y sus héroes (23) y el deseo de algún efecto de imagen positiva para el sindicato, puesto que del Mundial se pueden aprovechar todos..., protagonistas y allegados. $Y$ en una fase crítica como la que atenaza al sindicato, parece atrayente cualquier oportunidad para un poco de face-lifting - con lo anómala que parezca a la «tradición» o al sentido común de algún militante-. De aquí el específico acuerdo político entre confederaciones y los organizadores del Mundial, explicitado y sancionado públicamente el 10 de febrero de 1989. Según este acuerdo, durante el desarrollo del campeonato del mundo no habría agitaciones sindicales. Por supuesto, con los muertos y heridos en las obras el idilio sufre fuertes tensiones. Pero, significativamente, aquellos muertos y heridos provocan en el sindicato una renovada atención hacia la seguridad de la producción de las obras, con consiguientes reivindicaciones, agitaciones y huelgas, sin que el Mundial, en sí, acabe sobre el banco de los acusados y sin que su celebración llegue a ser un específico objetivo de protesta y lucha. Después se tomarán en consideración las múltiples experiencias de movilización mono-issue promovidas por agregaciones colectivas con base territorial determinada que han salpicado varios procesos decisionales, aun dejando al margen los movimientos ambientalistas. Estos últimos han jugado, por cierto, su previsible papel con amplio recurso a la magistratura, y especialmente en Roma, manifestándose actores de difícil «digestión» por parte del proceso decisional y de sus líderes. Pero, de por sí, no han representado una novedad. Los actores nuevos —o sea «ajenos»- han sido precisamente los diversos, episódicos pero numerosos «públicos atentos» que se han agregado, articulado y movilizado sobre cada cuestión referente a sus respectivos «territorios», que ha surgido, ha reaparecido

(22) Que ha encontrado un explícito reflejo en las relaciones industriales del grupo empresarial más importante del país. En la perspectiva de «Italia 90», la FIAT, con el aplauso de las confederaciones sindicales, propuso a los sindicatos anticipar cuatro horas la salida de los trabajadores del segundo turno en los días entre semana en que el equipo italiano debía jugar sus encuentros. En cambio los trabajadóres deberían sacrificar un sábado (La Repúbblica, 10 de febrero de 1990).

(23) Existen mil ejemplos de cómo el fútbol-espectáculo se presenta con su rostro amable, fiable, popular, populista y demagógico. Como muestra la portada de Rassega Sindacale, dedicada a Rud Gullit y a su solidaridad con Nelson Mandela. 
o se ha exasperado por la concomitancia con el Mundial y con las obras de su preparación. Emblemática es la cuestión florentina, sea por la decisión sobre la localización de la instalación para la gimnasia atlética que hubiera debido sustituir la pista suprimida del estadio municipal reestructurado, sea por las obras de «adorno urbano» que hubieran debido dar una digna cobertura al estadio rehecho. En ambas circunstancias estas decididas manifestaciones de «movilización consciente» de los habitantes no organizados de un barrio han expresado la consolidación «... de un vecindario interesado en buscar, sobre las problemáticas específicas que de cuando en cuando lo implican, las soluciones que se presenten como las más adecuadas (técnicamente, o mejor en términos de policy), evidenciando, en muchos casos, una actitud cognoscitivamente abierta y emotivamente fuerte» (24), que corta transversalmente al actor político-administrativo local, imponiendo a sus componentes de partido y burócratas el medirse con sus issues y sus policy preferences.

\section{CONCLUSIONES}

Para ahorrarle al hipotético lector un resumen del resumen me limitaré a tres observaciones finales muy generales sobre el asunto de los estadios como experiencia de Gobierno local:

a) Aun en los mencionados límites de mi estudio, la gama de los actores movilizados por las obras de los estadios es bastante reducida. $\mathrm{Y}$ ya he dicho que ha originado unas redes de relaciones muy definidas, compactas e integradas. Ello no significa que se ha tratado de relaciones y roles fácilmente predecibles o incluíbles en una sólida y unívoca muestra. Al contrario, la conducta de nuestros actores no está condicionada para nada por las respectivas funciones «estatutarias» y los papeles representados han seguido las modalidades y las lógicas de interacción que los diversos procesos decisionales han impuesto. Por otra parte, precisamente era ésta una de las hipótesis de trabajo más pacíficas, diría intrínseca a la misma orientación que elegimos.

En la cuestión de los estadios se podrían entrever ciertos intentos para definir y racionalizar ex ante los networks decisionales locales. $\mathrm{O}$ al menos, así se puede interpretar la espesa red de contactos, relaciones y finanzas que -antes, durante y después del decreto de urgencia sobre los estadios y los trabajos de infraestructura- ha conectado a algunos administradores locales y algunos actores centrales de toda la operación del Mundial (el ministro de Turismo, la cumbre del

(24) Así, Sergio FabBRINI, «Se l'esperto è il cittadino», en Rinascita, I (nueva serie), núm. 15, 20 de mayo de 1990, p. 47. 
CONI, la de la FIGC, la dirección del COL, parlamentarios de las comisiones de la Cámara y el Senado que se ocupan de Hacienda y Obras Públicas). Así como igualmente podría interpretarse aquel implícito papel de autbority central super partes que justo el COL y su management parecía que irían a asumir para "coordinar» los modos y los tiempos de los varios procesos decisionales.

Antes bien, sin forzar demasiado los reales y conscientes intentos del «legislador» y la heterogénesis de los fines que siempre alimenta sus opciones, parece que la legislación sobre el Mundial quisiera dotar una gran política pública de un apropiado y calibrado «Gobierno privado». Es decir, un estructurado y «fuerte» ejecutivo para la puesta en marcha; una poderosa cobertura de medios, de ideologías «débiles» e identidades patrióticas para la legitimación cultural y política; una fundamental instrumentación para prevenir y componer los conflictos entre los partidos, intereses y burocracias por medio de una distribución «cooperativa» de los recursos financieros, de las oportunidades económicas y de las responsabilidades políticas y administrativas.

Pero si realmente se hizo este esfuerzo para organizar y gobernar preventivamente el decision making local tal intento, en todo caso, lo absorbió el efectivo desarrollo de los procesos decisionales de las doce ciudades. En ellas el presumible «gobierno» del Mundial ha llegado a ser un elemento de contexto que vincula y no ha producido fuertes subjetividades específicas, capaces de imponerse a los actores locales y orientar su conducta. En todo caso, se haya tratado de intentos de coordinación reales o no, in loco se ha producido la determinación y conformación de los varios procesos decisionales, y es ahí donde se han definido el quién, el cómo, el cuándo de su desarrollo.

b) En el conjunto de los procesos examinados, la subjetividad autónoma de propuestas y planteamientos de la Administración pública local es reemplazada por particulares y bien identificados protagonistas político-administrativos. Estos saben aprovechar la oportunidad del Mundial para redefinir unas estrategias de policy ya presentes o en el horizonte de las agendas de sus respectivas Administraciones. Una vez más, la habilidad del administrador local que aspira a la «innovación» y a la «eficacia» de las políticas que preside le lleva a no comprometerse con la especificidad de las «demandas» y «necesidades» del público (y de las difíciles ponderaciones y agregaciones de las mismas). Y prefiere no seguir los vínculos propios de la política ni los diseños estratégicos que se conexionen con ello, para entregarse a su habilidad en el conocer y operacionalizar las posibilidades abiertas por hipótesis de trabajo ideadas en el exterior de su polity. Es decir, por obra de actores, en función de finalidad y sobre la base de motivaciones y oportunidades que están fuera del perímetro del Gobierno local y se mue- 
ven en dimensiones económicas y empresariales ajenas a la localidad (25).

El éxito de esta «accidentalidad» estratégica no presupone, de por sí, una coherencia autónoma de proyectos o programas del administrador público ni la eficiencia procesual y de procedimiento del sistema político-administrativo en que opera, sino que postula la capacidad de aquel mismo administrador para promover «comisiones» decisionales que sean bastante reducidas y compactas para tutelar cierta definición de la policy de la complejidad y contingencias de la política local. Y que sepan «desplazarse» a través de los partidos e instituciones del Gobierno local para resguardarse de los conflictos políticos contingentes, los objetivos de los actores que con aquella policy tienen una relación de interés más inmediata e intrínseca. Y si se trata de comisiones que preexisten a la iniciativa del administrador está en juego su capacidad de integrarse en posiciones de liderazgo, estimulando el crédito político y el consentimiento de que disponga, y los recursos legales y económicos que él pueda movilizar en favor de los objetivos agregados por la «comisión» y de las cbances económicas y políticas que sus miembros piensan tomar en las decisiones en discusión.

El administrador que demuestra esta propensión y habilidad para aprovechar las «oportunidades» externas de la dimensión local del planteamiento político y sabe estructurar el decision making territorial por medio de adecuadas comisiones de «decisiones y negocios» es, sin duda, un actor que facilita -en términos «cuantitativos»- los procesos de renovación urbana con las características de los examinados aquí. Que son, por otra parte, el género de procesos a los que parece se va a entregar, en gran parte, el cambio «proyectado» del paisaje (26) de ciudades y metrópolis en nuestro país.

c) Frente al dúctil y personalizado activismo de los administradores encargados de los estadios del Mundial, los partidos —en sus lógicas organizacionales y en sus propensiones estratégicas- parece que se condenan a una tendencial disolución. Los administradores que los representan en el Gobierno local no tienen con ellos ninguna relación sobre las cuestiones a decidir. Discutir sobre la oportunidad política de acoger el Mundial aparece -en los partidos y según los partidos-, evidentemente, sin sentido, pues la acción introducida es «... la oferta que no se puede rechazar». ¿Y quién se atrevería a contrastar la «legitimidad absoluta» del espectáculo futbolístico y de su máxima celebración nacional-cultural-televisiva? Por lo cual, cada partido relega la

(25) Para una visión general de esta problemática en su aspecto urbanístico, L. MAZZA, «Società locale e strategie economische: è possibile una convergenza nella política urbana?m, en A. BAGNASCO (ed.), «La Citta della Ford. Il Caso di Torino», op. cit., pp. 108-125.

(26) Aludo a la noción de «paisaje» como forma visible de territorio elaborada por A. PREDIER, Urbanistica, tutela del paesaggio, espropiazione, Giuuffré, Milán, 1969. 
predisposición del Mundial a las cuestiones de específica competencia «administrativa» y no «política». Por otra parte, toda la operación de «Italia 90» parte y se desarrolla en las mesas de pocos super-encargados de los trabajos, fuera de un real debate político sobre el sí y cómo darle acogida. Debate que nunca nadie ha solicitado realmente, ni en Parlamento ni en uno cualquiera de los municipios interesados (mientras las regiones han sido relegadas a una total ausencia). Pero - a parte de la intangibilidad política del fenómeno futbolístico- ¿quién habría negado la salubridad del golpe de látigo que el Mundial habría podido infligir al siempre lamentado estancamiento político y de proyectos de las ciudades y de sus Administraciones?

Aquí se inserta el interrogante que planea a lo largo de la investigación: ¿estamos frente a un «modelo» a contrastar, especialmente en el momento en que toda la estructura de los poderes locales se encamina hacia una «reforma» general? El pesimismo de la razón nos dice que no será algún concejal ecologista o nostálgico del «plan» quien va a parar procesos de tanta capacidad estratégica. Aun porque, a falta de grandes y fuertes ideas y en el crepúsculo del welfare local y de sus expectativas, a cualquier clase política — guste o no guste- le tentarán grandes y saludables proyectos, con plazo garantizado, y fuerte appeal popular. Y el «no» rotundo y previo dejará en el gueto a quien se atreva a pronunciarlo.

Una hipótesis realista de Gobierno local no puede no tomar nota de ello sin esperar los efectos taumatúrgicos de las reformas institucionales; las Administraciones locales (y regionales) deberían llegar a ser, al menos, interlocutores del gran planteamiento privado. Ello supone estructuras, recursos y burocracias adecuadas, pero -en primer lugar- que los partidos interesados se den unas pocas, pero netas, coordenadas estratégicas sobre el futuro del desarrollo metropolitano. De tal modo que el «tú mismo» de cada concejal tenga, por lo menos, un cuadro de referencia interpretativa. De otro modo, el Gobierno local estará condenado a ser siempre el eslabón más solicitado, pero también el más débil, de la democracia italiana y de su sistema administrativo (27).

\section{Traducción de ADA ARAgona}

(27) Una reflexión rica de sugestiones en esta perspectiva, sobre la base de una investigación pionera y muy rica de las «estrategias» y «direcciones» partidistas en la distribución política de los cargos municipales en los últimos veinte años, F. CAzzolA, L'anello debole. Chi, Dove. Quando nelle amministrazioni comunali, en curso de edición por Il Mulino, Bolonia. 
DA-1990-1991, núms. 224-225. MICHAEL BARZELAY. La responsabilidad en una perspectiva posbu...

DA-1990-1991, núms. 224-225. MICHAEL BARZELAY. La responsabilidad en una perspectiva posbu... 